DIW BERLIN

Discussion Papers

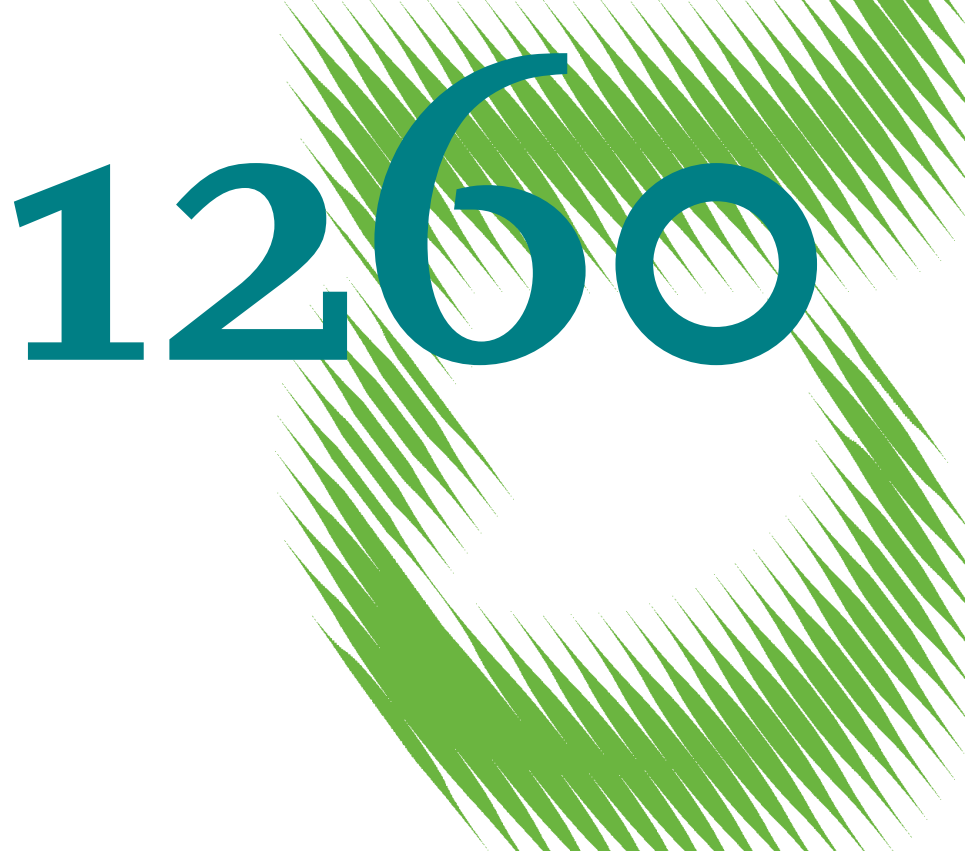

Getting back into the Labor Market: The Effects of Start-Up Subsidies for Unemployed Females 
Opinions expressed in this paper are those of the author(s) and do not necessarily reflect views of the institute.

IMPRESSUM

(C) DIW Berlin, 2012

DIW Berlin

German Institute for Economic Research

Mohrenstr. 58

10117 Berlin

Tel. $+49(30) 89789-0$

Fax +49 (30) $89789-200$

http://www.diw.de

ISSN print edition $1433-0210$

ISSN electronic edition 1619-4535

Papers can be downloaded free of charge from the DIW Berlin website:

http://www.diw.de/discussionpapers

Discussion Papers of DIW Berlin are indexed in RePEc and SSRN:

http://ideas.repec.org/s/diw/diwwpp.html

http://www.ssrn.com/link/DIW-Berlin-German-Inst-Econ-Res.html 


\title{
Getting Back into the Labor Market: The Effects of Start-Up Subsidies for Unemployed Females
}

\author{
Marco Caliendo* $\quad$ Steffen Künn ${ }^{\dagger}$
}

This version:

December 3, 2012

\begin{abstract}
A shortage of skilled labor and low female labor market participation are problems many developed countries have to face. Beside activating inactive women, one possible solution is to support the re-integration of unemployed women. Due to female-specific labor market constraints (preferences for flexible working hours, discrimination), this is a difficult task, and the question arises whether active labor market policies (ALMP) are an appropriate tool to do so. Promoting self-employment among the unemployed might be promising. Starting their own business might give women more independence and flexibility in allocating their time to work and family. Access to long-term informative data allows us to close existing research gaps, and we investigate the impact of two start-up programs on long-run labor market and fertility outcomes of female participants. We find that start-up programs persistently integrate former unemployed women into the labor market and partly improve their income situations. The impact on fertility is less detrimental than for traditional ALMP programs.
\end{abstract}

Keywords: $\quad$ Start-Up Subsidies, Evaluation, Long-Term Effects,

JEL: Female Labor-Force Participation, Fertility

J68, C14, H43

${ }^{*}$ University of Potsdam, IZA Bonn, DIW Berlin, IAB Nuremberg, e-Mail: caliendo@uni-potsdam.de. Corresponding address: University of Potsdam, Chair of Empirical Economics, August-Bebel-Str. 89, 14482 Potsdam, Germany. Tel: +49331977 3225. Fax: +493319773210.

${ }^{\dagger}$ IZA Bonn, University of Potsdam, e-Mail: kuenn@iza.org.

We thank Daniel S. Hamermesh, Andrew J. Oswald and participants at the 2012 Annual Meeting of the Society of Labor Economists (SOLE), the 2011 APPAM Fall Research Conference and seminars at IZA Bonn and University of Potsdam for helpful discussions and comments; and Anna Becker for excellent research assistance. Financial support of the IAB (Nuremberg) under the research grant No. 1007 is gratefully acknowledged. 


\section{Introduction}

Many developed countries already face, or will face, the problem of skilled labor supply shortage in the upcoming decades. This is accompanied in most cases with low female labor market participation. Within Organization for Economic Co-operation and Development (OECD) countries, only $61 \%$ of women of working age actively participated in the labor market in 2008; whereas the ratio is $80 \%$ for men. This gap is particularly alarming as women are on average higher educated, with better school degrees and higher shares of university graduates. Hence, activating this untapped skilled labor resource is a key issue in the current policy debate. However, the question remains how to do so. Beside activating economic inactive women, one possible solution is to support the re-integration of already active but unemployed women. Unemployed women are more likely than men to switch to inactivity with increasing unemployment duration, so a timely and sustainable re-integration is of particular importance. However, two problems occur: Eurostat reports that low participation rates among women are mainly driven by family related reasons, as they have to balance work and family life. This is confirmed by empirical evidence showing that female labor supply is very responsive to child care policies (Lefebvre and Merrigan, 2008; Schone, 2004; Gelbach, 2002) and that non-traditional work arrangements with a high degree of flexibility - such as home-based work-particularly attract women (Edwards and Field-Hendrey, 2002). Therefore, women's preferences for flexible working schemes and limited availability of those jobs (e.g., within the OECD, only $15 \%$ of jobs are part-time) makes an integration into the labor market difficult. The second problem occurs due to the low female labor market participation, as it might induce statistical discrimination, where employers tend to prefer men because the uncertainty about women's ability is higher (see Phelps, 1972). ${ }^{1}$ In addition to the concept of statistical discrimination, women might - following the theory of discrimination by Becker (1971) — be further hindered by taste-based decisions of employers. Prejudices against women may stem from expected working interruptions due to fertility or from sexist views of men about the appropriate role of women, i.e., housework and child care against labor market activity (see Charles, Guryan, and Pan, 2009, for a discussion and empirical evidence). Although tastebased discrimination is extremely hard to prove, studies by Goldin and Rouse (2000) and Neumark, Bank, and Van Nort (1996) provide evidence on the existence of discrimination against women within the hiring process, which are also reflected in recent initiatives to overcome sexual discrimination with the introduction of anonymous job applications (see Behaghel, Crépon, and Le Barbanchonz, 2012; Krause, Rinne, and Zimmermann, 2012).

Given those female-specific labor market constraints, the question arises whether active labor market policies (ALMP) are an appropriate tool to improve re-integration chances of unemployed women. Traditional ALMP programs, such as training, job search assistance, job creation schemes or wage subsidies, focus primarily on the integration into dependent employment, where flexible working schemes are limited and aforementioned types of discrimination might exist. Existing evaluation studies do indeed show that participation

\footnotetext{
${ }^{1}$ Evidence on the existence of statistical discrimination is provided by Dickinson and Oaxaca (2009) and Altonji and Pierret (2001), among others.
} 
in such programs leads to positive, but small, employment effects for women in general. However, the induced higher labor market attachment comes at the price of reduced fertility among female participants (Lechner and Wiehler, 2011; Bergemann and van den Berg, 2008). The OECD highlights the problem of declining fertility rates within OECD countries and its societal consequences, e.g., securing generational replacement and an aging population. To counteract this worrisome development, several OECD governments have already started to implement policies in the last decades (see Sleebos, 2003, for a summary of implemeted programs and empirical evidence on their effectiveness.). Against this background, Lechner and Wiehler (2011) conclude that traditional ALMP programs become ineffective for women if fertility is considered as important as employment.

Supporting self-employment among unemployed women might be a promising solution in both dimensions. Unemployed women start their own business which is detached from labor demand side restrictions and gives them more independence and flexibility in allocating their time to work and family. Therefore, start-up programs are likely to ease the integration of unemployed women without a simultaneous reduction in fertility. While the existing evidence on start-up programs confirms the promising expectations on employment prospects for unemployed women, long-term evidence is missing (due to data restrictions), and the impact on fertility is completely unexamined.

We have access to a rich data set which combines administrative and survey information and follows unemployed individuals in Germany for nearly five years after entering one of two distinct start-up programs. Germany is a good example as start-up programs are an integral part of the German ALMP system. Moreover, estimated effects might be applied to other countries as the characteristics of the unemployed female workforce in Germany is quite similar to those of other industrialized countries. ${ }^{2}$ The first program under scrutinybridging allowance (BA, "Überbrückungsgeld") — provides relatively high financial support (depending on individuals' previous earnings) to unemployed workers for the first six months after starting a business; whereas the second program - start-up subsidy (SUS, "Existenzgründungszuschuss") - consists of (lower) monthly lump-sum payments for up to three years. Due to the institutional setting both programs attract different types of individuals.

With the data at hand, we apply propensity score matching methods and compare female program participants with non-participants - comprising of other unemployed individuals - and contribute to the existing literature in three aspects: First, we provide longterm evidence of participation in start-up programs on employment and income prospects of initially unemployed women. In particular, the availability of different income measures allows for a more comprehensive evaluation of the program impact compared to existing studies. Second, we investigate the impact of subsidized self-employment among women on fertility. In addition to causal program analysis, we present extensive long-term descriptive evidence on the subsidized businesses. Beside evidence on business characteristics, survival and income situations of female founders, we address the question whether subsidized

\footnotetext{
${ }^{2}$ For instance, descriptive statistics by the German Federal Employment Agency and the U.S. Bureau of Labor Statistics show that the unemployed female workforce in Germany and the United States are both characterized by higher shares of re-entrants, having children and a higher education background than men.
} 
businesses also create additional jobs. This is referred to a "double dividend" and depictsin contrast to traditional ALMP programs - a very attractive feature associated with startup programs.

The paper is organized as follows: Section 2 addresses the question to what extent ALMP takes female-specific needs into account, formulates theoretical expectations about program effectiveness and summarizes previous findings on the impact of ALMP for unemployed women. Section 3 explains the institutional settings of the programs under scrutiny and describes the data set. Section 4 provides descriptive evidence on business founders and business performance. Section 5 contains the causal analysis with explanation of the identification and estimation strategy, and discussion of program effects including a sensitivity analysis. Finally, Section 6 concludes.

\section{Active Labor Market Policy and Gender Issues}

\subsection{Female Unemployment and Potential Effects of ALMP}

The different labor market constraints men and women encounter are reflected in the structure of the unemployed workforce. The unemployed female workforce is characterized by long-term unemployment, high shares of job-returnees and single parents. Unemployed women are on average more likely to leave the workforce with increasing unemployment duration, even though they are better educated than unemployed men. ${ }^{3}$ This raises the question whether and to what extent national ALMP take these gender differences into account. A recent comparative study by the European Commission shows that the majority of the 30 European countries made efforts to adjust their employment policies with respect to gender specific needs (see European Commission, 2008). For instance, Greek authorities provide higher subsidies to employers hiring lone parents and returnees, and Spain offers social security reductions for contracting women. We have no knowledge of gender-specific programs in Germany, so each measure provided by the Federal Employment Agency (FEA) based on the Social Act III is accessible by both unemployed men and women. However, the Social Act III, which regulates labor market policy in Germany, specifies gender equality, which leads to increasing female entries into ALMP and attempts to eliminate female-specific labor market barriers (see Müller and Kurtz, 2003). ${ }^{4}$ Rubery (2002) shows that the implementation of "Gender Mainstreaming" in the German labor market policy is relatively advanced in a European comparison and in particular, the access to ALMP programs has recently been simplified for job-returnees, who often are not eligible to unemployment benefits and hence face restricted access to ALMP.

However, the question remains how ALMP - given the gender differences in the composition of the unemployed workforce - is supposed to work. With a focus on unemployed women who are characterized by long-term unemployment, high shares of job-returnees,

\footnotetext{
${ }^{3}$ The German Federal Employment Agency reports for 2008 that among unemployed women, $51 \%$ have no or only a lower secondary school degree compared to $60 \%$ among unemployed men. Moreover, $19 \%$ (1\%) of unemployed women (men) are single parents and 37\% (30\%) left the labor force.

${ }^{4}$ Since January 1, 2003 the "Job-Aqtiv-Gesetz" became law and integrated the concept of "Gender Mainstreaming" as a cross-sectional target into German labor market policy.
} 
single parents and high risk of leaving the workforce, two outcomes are of particular interest: labor market participation in general and the integration into employment. Within a theoretical model that relies on the assumption that individuals participate in the labor market if the value of participation exceeds the value of non-participation, Johansson (2001) argues that ALMP is likely to have a positive impact on labor market participation. The value of labor market participation is higher for program participants compared to non-participants, as it directly or indirectly influences labor market income due to additional earnings during the program, renewal of benefit entitlement or higher job arrival rates afterwards. Johansson (2001) confirms the theory empirically and finds a positive effect on labor force participation for the case of Sweden.

With respect to ALMP and its impact on the employment probability of participants, theory predicts an increased employment probability of participants as participation increases the efficiency of the matching process between employers and workers due to an increase in human capital, employability or search intensity (Kluve et al., 2007). Beside this more general view, Bergemann and van den Berg (2008) focus on women and provide theoretical considerations on how ALMP might increase the employment probability of female participants. First of all, women face on average higher wage elasticities than men. This may be due to the fact that women need to reconcile more responsibilities when allocating their time, i.e., beside work and leisure, also child care or housework. The higher female wage elasticity induces higher reservation wages than offered by the market which in turn decreases female labor supply. Human capital enhancing ALMP programs might increase wage offers and (if those exceed individual reservation wages) make women accept jobs. The fact that the unemployed female workforce is characterized by a relatively high educational level in contrast to unemployed men weakens the validity of this argument. In line with this, Müller and Kurtz (2003) show for Germany that women are over-represented in schemes such as vocational training which is associated with a relatively low probability of re-integration. The main hurdle for unemployed women in Germany is hence obviously not a lack of human capital. The second aspect identified by Bergemann and van den Berg (2008) that determines the impact of ALMP on employment probabilities of unemployed women is the reduction of labor market distance. Labor market biographies of women are likely to be interrupted by maternity leave, child care or other family related reasons. Employers have therefore less information about women's productivity compared to men, which might lead them to have preferences for male workers (statistical discrimination). Programs which are directly associated with an integration in employment, such as wage subsidies, are most promising as they give potential employers the opportunity to learn about women's employability (which also reduces potentially existing prejudices). In addition, women start working and learning about their own opportunities in the labor market and about non-pecuniary utility of employment. Although wage subsidies are likely to reduce the labor market gap for women, program assignment is (in contrast to vocational training) not solely at caseworker's discretion but also the employer's. The assignment restriction leads therefore to an under-representation of women in those programs (see Müller and Kurtz, 2003). 


\subsection{The Case of Start-Up Subsidies}

Start-up subsidies, in contrast, are more promising as they are associated with the positive feature of wage subsidies (reduce distance to the labor market) but do not hinge on employer's decision. Unemployed women start their own business and therefore create their own job. The most common argument to justify start-up subsidies for the unemployed is based on the existence of capital market imperfections and that capital markets are likely to discriminate against unemployed individuals (see Meager, 1996; Perry, 2006). This results in a suboptimal rate of start-ups or undercapitalized businesses. Start-up subsidies aim to overcome these barriers and to remove financial disadvantages that the unemployed face compared to more wealthy individuals, including the coverage of the cost of living and social security during the critical founding period. Beside those differences to nonunemployed individuals, unemployed women in particular need to be supported. Theory predicts that individuals become self-employed if the expected discounted utility of being self-employed exceeds those of being in paid work (see Knight, 1921; Blanchflower and Oswald, 1998; Parker, 2009). As self-employment is considered to be very time consuming and associated with the risk of debts in the case of business failure, the expected utility of self-employment is particularly low for women because they are on average more risk averse and allocate less time to the labor market activities than men. ${ }^{5}$ Consistent with this, we observe that the share of self-employed women among all working women is lower than for men. Therefore, the existence of start-up subsidies might be particularly important for unemployed women in order to consider self-employment as an alternative to dependent employment. Our data do indeed show that unemployed women (in contrast to men) are more likely to start their own business on the advice of the employment agency.

Given that start-up subsidies increase entries into self-employment among unemployed women, the question arises whether start-up subsidies are a sensible strategy to re-integrate unemployed women. First of all, self-employment gives women more independence and flexibility in allocating their time to work and family which following descriptive statistics is one of the main reasons why unemployed women have difficulties finding a job. Second, even in the case of business failure, the self-employment experience is likely to increase women's employability, human capital and labor market networks which results in higher job finding probabilities afterwards. Beside these main advantages, start-up subsidies in contrast to traditional ALMP programs are potentially associated with a "double dividend", i.e., the subsidized businesses might create additional jobs in the future and hence reduce unemployment further. This is very attractive to policy makers. Beside the promising effects on an individual level, start-up subsidies might be further associated with positive macroeconomic impacts. The entry of new firms generally increases competition and consequently the productivity of firms. This potentially can promote efficient markets and technology diffusion and might finally lead to economic stability and economic growth (see Storey, 1994; Fritsch, 2008).

However, start-up subsidies might also have negative impacts. Similar to other subsidy

\footnotetext{
${ }^{5}$ Based on a cross-country study Bönte and Jarosch (2011) provide empirical evidence that gender differences in competitiveness and risk preferences significantly contribute to the gender gap in entrepreneurship.
} 
programs, start-ups subsidies might be affected by deadweight effects. Following Caliendo and Kritikos (2010), deadweight effects in the case of start-up subsidies are (in contrast to wage subsidies) hard to determine as two criteria have to be fulfilled: the individual would have become self-employed even without financial support, and business success is not influenced by the subsidy. Both aspects are hard to measure and reliable estimates hardly exist. ${ }^{6}$ Start-up subsidies might further generate displacement or substitution effects, i.e., incumbent firms or non-subsidized start-ups may be displaced or firms may substitute employees by subsidized self-employed workers. Due to a highly regulated labor market in Germany, however, substitution effects are less likely to occur, and Martin and Grubb (2001) argue that displacement effects - if at all - are only valid in the short-run, as the positive labor supply effects stimulated by wage subsidies lead certainly to an increase in aggregate employment (due to macroeconomic adjustments) in the medium- to long-term.

\subsection{Previous Evidence on the Effectiveness of ALMP}

The evidence on the effectiveness of traditional ALMP programs for unemployed women in Germany is mixed. For instance, training measures (short-term training, classroom or practical training, and retraining) are ineffective in improving employment prospects in the short- to medium-run but generate small positive effects in the long-run (see Biewen, Fitzenberger, Osikominu, and Waller, 2007; Fitzenberger, Orlyanskaya, Osikominu, and Paul, 2012). Compared to men, Fitzenberger et al. (2008) show that training programs generate larger employment effects for women in West Germany. Caliendo, Hujer, and Thomsen (2008) find that job creation schemes fail to integrate unemployed women into the labor market. They do not find substantially different effects for men but instead between East and West Germany. In a broader survey for OECD countries, Martin and Grubb (2001) review results of several evaluation studies on ALMP and conclude that training measures (such as classroom or on-the-job training), job search assistance and employment subsidies are helpful for women to exit unemployment, while job creation schemes fail. The survey also shows a gender gap in terms of program effects. Although effects are small (in particular in terms of earnings), they are always more favorable for women. In a more recent study on Europe, Bergemann and van den Berg (2008) confirm this finding and show that ALMP is generally associated with positive employment effects for women which are larger than those for men (in particular in regions with low female labor market participation). Regarding this gender gap, Lechner and Wiehler (2011) show that higher employment effects for women in Austria can be explained by higher shares leaving the workforce among female non-participants, which does not apply to male nonparticipants. Disaggregating periods out of the labor force, the authors show that program participation increases labor market attachment of female participants but simultaneously reduces fertility. If fertility is considered to be as important as employment from a societal perspective, then programs become ineffective for unemployed women.

We now want to compare the overall disappointing evidence on the effectiveness of

\footnotetext{
${ }^{6}$ Recent descriptive evidence on a start-up subsidy program in Germany indicates that deadweight effects are rather small and range between 7-19\% (see Caliendo, Hogenacker, Künn, and Wießner, 2012).
} 
traditional programs with respect to employment (evidence on earnings hardly exist) to existing evidence on start-up programs. At least to our knowledge, there are only few comparable studies that show female-specific effects. Caliendo (2009) presents preliminary evidence on the effects of the two programs we also consider in this paper and finds positive employment and no significant income effects. However, he emphasizes that the validity of his results is limited, as some individuals still received financial support and further longterm evidence is important to draw policy-relevant and reliable conclusions. Cueto and Mato (2006) consider self-employment subsidies in Spain and find high survival rates of approximately $93 \%$ after two years and $76 \%$ after five. In a gender analysis, they conclude that men's survival is predominately related to the economic situation (main source of household income), while women's survival depends mainly on individuals characteristics (marital status, education). Almeida and Galasso (2010) investigate the short-term impact (12 months) of financial and technical assistance for welfare beneficiaries on their way to self-employment in Argentina. They show that women in particular are likely to start a business parallel to having another job and find no significant income gain due to the program. Kelly, Lewis, Mulvey, and Dalzell (2002) consider an allowance paid up to 52 weeks as well as training and counseling in Australia. Three years after start-up, $55.4 \%$ of female businesses had survived. While survival rates are approximately the same size for men, women work fewer hours. O'Leary (1999) considers self-employment schemes for Hungary and Poland. While the program in Poland consists of loans at market interest rates combined with the option that $50 \%$ of repayments will be waived if firms survive at least two years, the Hungarian program pays unemployment benefits for up to 18 months. O'Leary (1999) finds large and positive employment effects for female participants in both countries. Earning effects are only positive in Hungary and negative in Poland. ${ }^{7}$

The existing evidence indicates that the idea of supporting unemployed women to become self-employed is quite promising and much more positive than for traditional programs. Moreover, evidence indicates that women use self-employment in a flexible way (parallel to other jobs, fewer working hours). However, long-term evidence is important but still missing and evidence on earnings is scarce.

\section{$3 \quad$ Institutional Setting and Data}

\subsection{Institutional Setting in Germany}

In this study, we investigate the impact of two distinct start-up programs, which basically differ in terms of length and amount of the subsidy. The first program, the bridging allowance (BA), amounts to the individual unemployment benefits plus a lump sum payment (68.5\% of benefits) for social security and is paid during the first six months of self-employment. ${ }^{8}$ To receive the subsidy the unemployed have to be eligible for unemploy-

\footnotetext{
${ }^{7}$ O'Leary (1999) primarily attributes the negative earning effect in the case of Poland to firms' reluctance in full disclosure to the tax authorities.

${ }^{8}$ On average, BA female participants in our data set received $€ 840$ in unemployment benefits per months during their unemployment spell. Given the additional lump sum payment for social security, this corresponds to an average BA payment of $€ 1,415$ per months.
} 
ment benefits and to present an externally approved business plan (issued by the regional chamber of commerce). While the BA was introduced in 1986, the second program, the start-up subsidy (SUS), was introduced as part of a more expansive labor market reform in 2003. The main intention for the introduction of a second program was to encourage small business start-ups by opening the program to a larger group of unemployed individuals. Eligibility to SUS was therefore not restricted to unemployed individuals with benefit entitlement but was also open to those with means-tested social assistance, i.e., primarily long-term unemployed and individuals with limited labor market experience (e.g., women). SUS consists of a lump-sum payment of $€ 600$ per month in the first year, $€ 360$ per month in the second and $€ 240$ per month in the third year. In contrast to BA, SUS was only approved (yearly) if self-employment income did not exceed $€ 25,000$ per year. SUS applicants did not have to submit business plans for prior approval and parallel receipt of BA and SUS was excluded. Due to the institutional framework, it was rational to choose BA if unemployment benefits were fairly high or if the income generated through the start-up firm was expected to exceed $€ 25,000$ per year. Both programs were replaced in August 2006 by a single new program - the new start-up subsidy program ("Gründungszuschuss") — which will not be analyzed here. ${ }^{9}$

In addition to the program-specific setting, two more regulations with respect to selfemployment in general have to be mentioned. First, other institutions such as federal state governments or the chamber of commerce offer additional programs to encourage self-employment, such as counseling, preparatory courses or subsidized loans. Second, selfemployment is highly restrictive in some professions in Germany, when compared to other countries. For some "typical" self-employed occupations (physicians, lawyers, etc.) and several handcraft occupations, an advanced certificate is required to become self-employed. However, Cressy (1996) argues that such preconditions for entry into self-employment tend to significantly enhance the survival of businesses.

\section{INSERT TABLE 1 ABOUT HERE}

Table 1 provides an overview of entries into start-up programs as well as other ALMP programs in Germany. Due to simplified eligibility criteria, it was unemployed women in particular who took advantage of the introduction of the SUS in 2003 (see Caliendo and Kritikos, 2010). In 2003, only $26 \%$ of BA participants were female in contrast to $41 \%$ for SUS. Moreover, in comparison to other programs, it is visible that the promotion of self-employment is one of the largest fields of ALMP in Germany. In fact, entries into SUS and BA exceed the number of entries into wage subsidies in 2003 and 2005.

\footnotetext{
${ }^{9}$ The new start-up subsidy consists of unemployment benefits and a lump-sum payment of $€ 300$ per month for social coverage paid for nine months. After that, the lump-sum payment of $€ 300$ may be extended for a further six months if the business is the full-time activity of the applicant. See Caliendo and Kritikos (2009) for information and a critical discussion of the features of the new program.
} 


\subsection{Data}

For the empirical analysis we use data on entries into SUS and BA in the third quarter of $2003^{10}$ and other unemployed individuals who did not enter SUS or BA in the same period as a control group. ${ }^{11}$ The data combines administrative data from the FEA with information from a telephone survey. ${ }^{12}$ The survey was conducted in three interview waves: two interviews in January/February of 2005 and 2006, and the last interview in May/June 2008. Finally, the data contain detailed information on individual socio-demographics and labor market history before treatment, program-specific aspects and different labor market outcomes up to five years after start-up.

\section{INSERT TABLE 2 ABOUT HERE}

We restrict our analysis to individuals who participated in every interview in order to observe individual labor market outcomes for the entire period of 56 months. Table 2 provides the number of individuals used in our analysis separated by gender and region. For the case of women in East Germany, we observe 186 former participants in SUS, 136 in BA and 271 non-participants.

\section{Descriptive Evidence on Female Start-Ups Out of Unem- ployment}

Based on observations depicted in Table 2, this section presents descriptive statistics on subsidized firms out of unemployment measured at two different points in time: at business start-up and 56 months later. Thereby, we focus on female founders and address two questions: 1) Who are the female business founders? and 2) How do they perform over time? We highlight significant differences to both their male counterparts and female non-participants where appropriate. We present results separately by region, as East and West Germany are characterized by significantly different labor market conditions. West Germany faces on average more favorable labor market conditions compared to East Germany, i.e., lower unemployment rates, relatively more vacancies etc. Although those regional differences smooth over time, they were prevalent at start-up in 2003. Note that all descriptive results presented below are adjusted for selection bias due to panel attrition by using sequential inverse probability weighting (see Wooldridge, 2002). ${ }^{13}$

\footnotetext{
${ }^{10}$ Having access to only one particular quarter of entrants bears the risk of a selective sample. However, comparing the distribution of certain characteristics (e.g., age and educational background) across different quarters does not show any significant differences.

${ }^{11}$ However, individuals in the control group are allowed to participate in ALMP programs afterwards. The actual number of non-participants who participated in ALMP programs after the third quarter 2003 is rather low. Approximately $15 \%$ of all non-participants were assigned to ALMP programs and only $2 \%$ participated in SUS or BA within our observation period.

${ }^{12}$ For a more extensive discussion of data construction see Caliendo and Künn (2011).

${ }^{13}$ The willingness of individuals to participate in the survey decreased over time. On average, we observe $46 \%$ of all participants and $40 \%$ of all non-participants for the entire period of 56 months. The attrition induced a positive selection, i.e., individuals who perform relatively well in terms of labor market outcomes are more likely to respond. Therefore, we use sequential inverse probability weighting to adjust for selective
} 


\subsection{Who Are the Female Business Founders?}

Table 3 shows descriptive statistics with respect to individual characteristics of female participants (Panel A) and aspects of the founding process (Panel B). Induced by the institutional settings both programs attract different types of individuals (as already noted by Caliendo and Kritikos, 2010). The less restrictive eligibility criteria for SUS provide individuals without (or elapsed) benefit entitlement - e.g., individuals with little labor market experience or long-term unemployed - access to start-up subsidies. Hence, it is not surprising that it is particularly used by women with strong family ties and therefore probably less labor market experience (resulting in low or even no unemployment benefit entitlement). Table 3 shows that $56 \%$ of female SUS participants in West Germany are married and $49 \%$ have children compared to $37 \%$ and $25 \%$ of the participants in BA. For East Germany however, these shares are overall large (64-70\% are married, $46 \%$ have children) and do not considerably differ between female BA and SUS participants. This might be explained by higher female labor market participation ${ }^{14}$ in East Germany which increases the share of unemployed women with unemployment benefit entitlement and therefore eligibility to BA. This explains why the less restrictive eligibility criteria for SUS are more important for unemployed women in West Germany. Moreover, as the amount of the subsidy depends on the level of unemployment benefits in the case of BA, this program attracts in particular better educated individuals as they are more likely to have higher past earnings and therefore higher benefit entitlement.

Given the composition of BA female participants, i.e., better educated with higher earnings in the past and lower family ties, we see that female BA participants (compared to SUS) more often report to be motivated by being their own boss, establish higher capitalized businesses and consider the subsidy to be less important for the founding decision. This reinforces the hypothesis that BA female participants are similar to "general" average business founders while SUS participants are rather "atypical" (compare Caliendo and Kritikos, 2010). However, female participants in both programs report "termination of unemployment" as their main motive.

\section{INSERT TABLE 3 ABOUT HERE}

In a next step, we compare female participants to both female non-participants and male business founders in order to identify program- and gender-specific selection patterns. The main aim is to shed light on the question whether primarily women with strong family obligations choose start-up programs and to what extent their businesses differ to those by male counterparts. Therefore, Table A.1 in the Appendix shows such a comparison with respect to individual characteristics (Panel A) and aspects of the founding process (Panel B) as presented in Table 3. The first two columns present results for female SUS (upper part) and BA (lower part) participants in West and East Germany, while columns three and four show the respective differences to female non-participants, where positive

attrition. However, the causal analysis relies on unweighted outcome variables, as participants and nonparticipants are similarly affected by selection, due to panel attrition.

${ }^{14}$ The FEA reports a female labor market participation of $63.6 \%$ in West Germany and $71.4 \%$ in East Germany for 2003. 
numbers denote higher values for female participants. Finally, columns five and six contain respective differences to male business founders.

The comparison to female non-participants reinforces the program-specific pattern. BA attracts better educated individuals with higher benefit entitlement and lower family ties, whereas participants in SUS have similar family ties and are slightly lower educated than the average non-participant. On top of that, female business founders are more risk loving than female non-participants which supports the hypothesis that self-employment particularly attracts women with higher risk preferences.

Compared to male business founders, women are better educated and have stronger family ties, i.e., they are more likely to being married and having children (except for the BA case in West Germany). Moreover, female participants seem to have different motivations to start their own business (men report more often "being the own boss") and tend to invest less. For instance, women are approximately 10\%-points more likely to cap their initial investment to a maximum of $€ 1,000$. The decision to become selfemployed also depends much more on the existence of the subsidy for women (except the BA case in West Germany). This might indicate that self-employment was probably not the preferred strategy of unemployed women but rather served as an alternative exit out of unemployment as they probably have to reconcile work and family.

\subsection{How Do They Perform Over Time?}

Given this indication that becoming self-employed was probably not the preferred strategy of female participants together with findings by Ehlers and Main (1998), who show that supporting low-income, minority women in the United States fosters labor market segregation of those women, it is very important to consider long-run labor market outcomes. First of all, Panel A in Table 4 shows that the majority of SUS and BA female participants are still self-employed five years after start-up. In fact, around $58 \%$ of female former SUS participants are self-employed and for BA participants the corresponding share is $67 \%$ in West Germany and 58\% in East Germany. ${ }^{15}$ The overall labor market integration-into self-employment or regular employment subject to social security contribution - is even higher and amounts to $76 \%$ in the SUS case and 90\% (82\%) for BA in West (East) Germany. It seems that participation in SUS and BA - even in the case of business failureaffects the probability of finding regular employment positively, e.g., due to labor market networks (contact to business partners) or an increase in employability and human capital. The unconditional comparison to non-participants shows higher shares in employment and lower shares leaving the workforce. For female BA participants in West Germany the differences are large; the employment probability for non-participants is $42.2 \%$-points lower and the probability that they have left the workforce is $11.5 \%$-points higher. This reflects the vulnerability of female labor market attachment, e.g., due to limited flexible working schemes in dependent employment. Table 4 also shows that female participants experience higher working and equivalent income than non-participants 56 months after

\footnotetext{
${ }^{15}$ Roughly $90 \%$ of these individuals were continuously self-employed throughout this period of 56 months. Among female participants whose businesses failed only $21-35 \%$ retained debts, of which around $70 \%$ reported debt of less than $€ 1,000$. The maximum amount of indebtedness is $€ 2,500$.
} 
start-up (Panel B). With respect to fertility outcomes, Panel C shows higher shares of non-participants with at least one spell in maternity or parental leave within our observation window indicating reduced fertility among female participants (except for the case of SUS in East Germany).

\section{INSERT TABLE 4 ABOUt HERE}

With respect to business development in terms of further job creation (double dividend), Panel D in Table 4 shows that self-employed women tend to operate primarily as solopreneurs: only $20 \%$ (30\%) of female SUS (BA) participants have at least one employee 56 months after start-up. Conditional on having at least one employee, SUS female participants employ on average two employees, while BA participants have three to five employees, corresponding to approximately one to two full-time equivalents in case of SUS and two to three in the BA case. Even though women tend to have smaller businesses compared to men, the double dividend argument is also true for female subsidy recipients. Furthermore, we see that self-employed women report an improved satisfaction in terms of type of activity compared to their previous dependent employment. It seems that they enjoy being self-employed.

In summary, the descriptive evidence indicates a high and persistent labor market integration of female former subsidy recipients. Moreover, it suggests an improved income situation compared to non-participants and reduced fertility. In order to finally conclude whether the promotion of self-employment is a sensible strategy to improve labor market outcomes without reducing fertility among female participants causal evidence is required. This is the objective of the remaining part of the paper.

\section{Empirical Analysis}

\subsection{Identification and Estimation of Causal Effects}

In order to estimate causal effects, we base our analysis on the potential outcome framework, also known as the Roy (1951) - Rubin (1974) model. The two potential outcomes are $Y^{1}$ (individual receives treatment, $D=1$ ) and $Y^{0}$ (individual does not receive treatment, $D=0$ ) whereby the observed outcome for any individual $i$ can be written as $Y_{i}=Y_{i}^{1} \cdot D_{i}+\left(1-D_{i}\right) \cdot Y_{i}^{0}$. As the treatment effect for each individual $i$ is then defined as $\tau_{i}=Y_{i}^{1}-Y_{i}^{0}$ and both potential outcomes are never observed for the same individual at the same time (referred to as the fundamental evaluation problem), we focus on the most prominent evaluation parameter, which is the average treatment effect on the treated (ATT):

$$
\tau_{A T T}=E\left(Y^{1} \mid D=1\right)-E\left(Y^{0} \mid D=1\right) .
$$

The last term on the right hand side of equation (1) describes the hypothetical outcome without treatment for those individuals who received treatment. Since the condition $E\left(Y^{0} \mid D=1\right)=E\left(Y^{0} \mid D=0\right)$ is usually not satisfied with non-experimental data, 
estimating ATT by the difference in sub-population means of participants $E\left(Y^{1} \mid D=1\right)$ and non-participants $E\left(Y^{0} \mid D=0\right)$ will lead to a selection bias, as participants and non-participants are likely to be selected groups in terms of observable and unobservable characteristics with different outcomes, even in the absence of the program. ${ }^{16}$ We apply propensity score matching and thus rely on the conditional independence assumption (CIA), which states that conditional on observable characteristics $(W)$ the counterfactual outcome is independent of treatment $Y^{0} \amalg D \mid W$, where $\amalg$ denotes independence. In addition to the CIA, we also assume overlap $\operatorname{Pr}(D=1 \mid W)<1$ for all $W$, which implies that there are no perfect predictors which determine participation. These assumptions are sufficient for identification of the ATT based on matching (MAT), which can then be written as:

$$
\tau_{A T T}^{M A T}=E\left(Y^{1} \mid W, D=1\right)-E_{W}\left[E\left(Y^{0} \mid W, D=0\right) \mid D=1\right],
$$

where the first term can be directly estimated from the treatment group and the second term from the matched comparison group. The outer expectation is taken over the distribution of $W$ in the treatment group.

As direct matching on $W$ can become hazardous when $W$ is of high dimension ("curse of dimensionality"), Rosenbaum and Rubin (1983) suggest using balancing scores $b(W)$ instead. These are functions of the relevant observed covariates $W$ such that the conditional distribution of $W$ given $b(W)$ is independent of the assignment to treatment, i.e., $W \amalg D \mid b(W)$. The propensity score $P(W)$, i.e., the probability of participating in a program, is one possible balancing score. For participants and non-participants with the same balancing score, the distributions of the covariates $W$ are the same, i.e., they are balanced across the groups. Hence, the identifying assumption can be re-written as $Y^{0} \amalg D \mid P(W)$ and the new overlap condition is given by $\operatorname{Pr}(D=1 \mid P(W))<1$.

The CIA is clearly a very strong assumption and its justification depends crucially on the availability of informative data which allow to control for all relevant variables that simultaneously influence the participation decision and the outcome variable. Economic theory, a sound knowledge of previous research, and information about the institutional setting should guide the researcher in specifying the model (see Smith and Todd, 2005 or Sianesi, 2004). Although there is no common rule on the set of information necessary, Lechner and Wunsch (2011) identify personal and firm characteristics of previous employment as well as labor market history, detailed information on the current unemployment spell and regional characteristics to be most important to include when estimating program effects of ALMP. We have both administrative and survey information available that allows us to mostly reproduce the set of information as suggested by Lechner and Wunsch (2011). In addition, we include information on intergenerational transmission, as those variables have been shown to significantly influence the start-up decision (see Caliendo and Künn, 2011). Although the justification of the CIA is not directly testable with non-experimental data, we argue that having these informative data available makes the CIA likely to hold in our application. However, to finally convince the readership that the CIA is a plausible assumption in our study, we also provide an extensive sensitivity analysis in Section 5.4

\footnotetext{
${ }^{16}$ See Caliendo and Hujer (2006) or Imbens and Wooldridge (2009) for further discussion.
} 
where we test the robustness of our results with respect to unobserved differences between participants and non-participants.

For identification of causal effects, any general equilibrium effects need to be excluded, i.e., treatment participation of one individual can not have an impact on the outcomes of other individuals. This assumption is referred to as the stable-unit-treatment-valueassumption (SUTVA). Imbens and Wooldridge (2009) argue that the validity of such an assumption depends on the scope of the program as well as on resulting effects. They infer that for the majority of labor market programs, the SUTVA is potentially fulfilled because such programs are usually of small scope with rather limited effects on the individual level. We follow their argumentation and refer to Table 1, where we see that entries into SUS and BA are approximately of the same scope as other ALMP programs and in relation to the total number of entries into unemployment of 7.6 million in 2003 quite small.

\subsection{Estimation Procedure}

To estimate the propensity scores of program participation versus non-participation for unemployed women, we apply a non-linear probit-estimation. We test different specifications following economic theory and previous empirical findings as outlined above. In addition, we check econometric indicators such as significance of parameters or pseudo- $\mathrm{R}^{2}$ to finally determine one preferred specification. ${ }^{17}$ Results of the probit-estimation are depicted in Table A.2, in the Appendix.

In particular, information on age, the previous unemployment spell (including duration and benefit level), employment status before job seeking and whether parents were/are self-employed determine selection into the program. In fact, the reverse influence of the unemployment benefit level on the decision to take up BA or SUS is due to the institutional setting. As the amount of the subsidy directly depends on the unemployment benefit level, individuals with higher previous earnings, and hence higher benefit levels, are more likely to choose BA. Furthermore, with particular respect to selection into BA in West Germany, the regional cluster and desired working time significantly influence the participation decision. The latter shows that women with strong preferences for full-time employment are more likely to start a business, reinforcing the hypothesis that BA female participants are rather similar to a general business founder type. However, we do not find any significant selection due to educational differences or household characteristics. Moreover, it is interesting to note that marital status and number of children do not significantly influence program participation, indicating that women with strong family obligations are not overrepresented in the programs, compared to the population of unemployed women.

The resulting distribution of the estimated propensity scores is depicted in Figure A.1, in the Appendix. As we can see, the distribution of the propensity scores are biased towards the tails, i.e., participants have a higher probability on average of becoming selfemployed than non-participants. Nevertheless, participant's propensity score distribution completely overlaps the region of the propensity scores of non-participants fulfilling the

\footnotetext{
${ }^{17}$ For a more extensive discussion on the estimation of propensity scores, we refer to Heckman, Ichimura, Smith, and Todd (1998) and Caliendo and Kopeinig (2008) among others.
} 
overlap assumption.

To estimate the average treatment effects on the treated as depicted in Equation 2, we apply Kernel-matching by using an Epanechnikov Kernel with a bandwidth of $0.06 .{ }^{18}$ This has in contrast to other matching algorithm (e.g., k-Nearest-Neighbor) the advantage of increased efficiency and allows bootstrapping to draw inference (see Caliendo and Kopeinig, 2008; Abadie and Imbens, 2008).

Table A.3 in the Appendix provides different statistics to assess the resulting matching quality, i.e., whether the matching procedure sufficiently balances the distribution of observable variables between participants and non-participants. Among many other assessment tests, we choose a simple comparison of means ( $t$-test), the mean standardized bias (MSB) and the Pseudo- $\mathrm{R}^{2}$ of the probit-estimation in the matched and unmatched sample respectively. ${ }^{19}$ The number of variables we control for varies between 50 and 56 in the PS estimation (depending on the specification). After matching, the null hypothesis of equal means in a one-sided 5\% significance $t$-test is rejected for one to four variables only. As results from a t-test alone do not reveal overall bias reduction, we also provide the MSB, which is defined as the differences in covariate means as a percentage of the square root of the average sample variances of the treatment and control group, whereby it is generally assumed that a MSB below $5 \%$ reflects a well-balanced covariate distribution in the sample. For women in West Germany, the MSB is below 5\% after matching. The higher MSB for women in East Germany might be due to two reasons. First, the number of observation is lowest for women in East Germany, which increases the bias as outliers receive relatively higher weights (see Table 2). Second, the predictive power of the PS estimation is relatively low as only a few variables significantly influence the participation decision (in particular for BA, compare Table A.2). For women in East Germany, the MSB drops from $11.8 \%$ in the unmatched to $6.5 \%$ in the matched sample for the SUS case; for BA from $13.9 \%$ to $8.3 \%$. Therefore, the matching procedure considerably reduces the bias for women in East Germany. However, the results have to be interpreted with caution. Finally, we re-estimate the propensity scores within the matched samples, as suggested by Sianesi (2004). The distribution of covariates should be well balanced within the matched sample, and hence the resulting pseudo- $\mathrm{R}^{2}$ from the PS estimation should be rather low. In fact, we do observe a sharp drop for all cohorts. Overall, we conclude that the applied PS matching procedure yields a control group that is very similar to the treatment group with respect to their observable characteristics at point of entry into treatment.

\subsection{Estimation Results}

To answer the two remaining research questions, i.e., long-term evidence of participation in start-up programs on employment and income prospects, and whether and to what extent, do start-up programs reduce fertility among female participants, we define different

\footnotetext{
${ }^{18}$ Using an Epanechnikov Kernel has the advantage that is puts distance-based weights to control observations and is bounded in its support, i.e., control observations with a distance to participants in terms of propensity scores larger than 0.06 are not considered. For sensitivity checks with respect to the choice of the estimation method see Section 5.4.

${ }^{19}$ See Caliendo and Kopeinig (2008) for a more detailed discussion of matching quality issues.
} 
outcome variables. To assess the employment prospects, we use "self-employed or regular employed" as a binary outcome variable which is one for individuals who are either employed subject to social security contribution or self-employed and zero otherwise. We use this due to two reasons. First, non-participants are less likely to become self-employed than participants, and hence comparing participants and non-participants with respect to selfemployment would bias the causal effects upwards. Second, the main objective of ALMP is to integrate individuals into the labor market, which includes being regular employed as a success.

To assess the impact on income prospects, we choose to consider individual monthly working income and monthly equivalent income, which reflects the income situation of the household. As non-working women have zero working income, and employment status differs between participants and non-participants, we also conduct a conditional analysis where we consider working income of full- or part-time employed ( $\geq 15$ hours/week) individuals only. This detailed income analysis depicts a main contribution to the existing literature, as evaluation studies on start-up programs mostly focus on employment outcomes and - due to data restrictions - often ignore the impact on income.

Finally, to address the question of whether start-up programs effect fertility outcomes of female participants and whether this outweighs employment effects (as it has been found for traditional ALMP programs), we consider two more outcome variables: First, the binary outcome variable "maternity or parental leave", which is one for individuals in respective spells and zero otherwise. ${ }^{20}$ This variable indicates whether there is a difference in childbearing between participants and non-participants. And second, we consider the binary outcome variable "self-employed, regular employed or in maternity or parental leave", which is one if the individual is in employment or maternity or parental leave and zero otherwise. This variable considers fertility to be as important as employment and shows whether effects on fertility outweigh those on employment.

Table 5 summarizes the estimated ATT, i.e, the difference in the defined outcome variables between female participants and matched non-participants.

\subsubsection{Employment and Income Prospects}

First of all, with respect to the probability of being "self-employed or regular employed", the positive and significant results in Table 5 show that both programs successfully integrate former unemployed women in the labor market in the long-run. We see that at the end of our observation window (56 months after start-up), when the last subsidy payment in case of SUS was at least two years and in case of BA even four years ago, SUS female participants had a 25.5 (37.8)\%-points higher employment probability compared to nonparticipants in West (East) Germany; 23.2 (33.1)\%-points for the BA case. Comparing

\footnotetext{
${ }^{20}$ Due to the average age of women in our sample of about 40 years at start-up, only a minority of $6-10 \%$ of female participants experiences maternity or parental leave at all (compare Table 4). We nevertheless consider this as an outcome variable to assess the impact on fertility, as the age distribution among treated and matched non-treated individuals is identical so that the share at risk to experience maternity or parental leave is identical in both groups, too. Furthermore, we have no direct information on childbearing or child care available which would allow for a broader consideration of reconcilability of work and family.
} 
these estimated employment effects to those for traditional ALMP programs underlines the success of SUS and BA and further supports the hypothesis that self-employment allows women to reconcile work and family. For instance, Biewen et al. (2008) report employment effects of 5-10 (5)\%-points for training programs 30 months after program start and Caliendo, Hujer, and Thomsen (2008) find -1 (5)\%-points for job creation schemes in West (East) Germany 36 months after program start.

Finally, we cumulate the monthly employment effects over the entire observation window, which shows that female SUS participants in West (East) Germany spent on average 26.9 (29.8) months more in self-employment or regular employment compared to female non-participants. These effects are quite large when taking into account that the observation window consists of 56 months in total. Again, due to a shorter period of funding (up to three years for SUS, compared to six months for BA) and therefore smaller locking-in at the beginning of the observation window, cumulated effects for BA participants are slightly smaller and amount to 20.6 (25.9) months in West (East) Germany. Comparing our results to those by Caliendo and Künn (2011) for men (in West Germany only), we find that the estimated employment effects of SUS and BA are larger for women-which is consistent with findings of other studies on traditional ALMP programs (compare Section $2.3)$.

\section{INSERT TABLE 5 ABOUT HeRE}

To answer the question whether higher employment probabilities also translate into higher incomes for participants, we now consider the ATT with respect to income variables measured 56 months after start-up (see Table 5). Regarding monthly working income the estimated effects for all participants are significantly positive in East Germany (€348 for SUS and $€ 334$ for BA) but insignificant in West Germany. Although female participants have higher employment probabilities 56 months after start-up, participation does not lead to a clear increase in working income. Conditional on being full- or part-time employed, any statistically significant effect on monthly working income disappears. The rather disappointing evidence on working income (compared to the positive effects on employment outcomes) might be due to two reasons: First, women opt for self-employment not to maximize working income but due to limited employment prospects in the regular labor market; and the zero effect on working income for female participants might then be interpreted as an opportunity cost for being employed. ${ }^{21}$ Second, the large observation window of 56 months might still be too short and additional human capital accumulation among female participants (strong positive employment effects) takes more time to translate into an income gain.

The effects with respect to equivalent household income are positive and (in contrast to working income) statistically significant throughout for female participants. This in-

\footnotetext{
${ }^{21}$ This is confirmed by descriptive evidence. Female participants earn on average 8-9 $€$ /hour ( $7 € /$ hour) from their self-employed activity 56 months after start-up in West (East) Germany. The Federal Statistical Office reports net hourly wages of $€ 12$ and $€ 10$ in West and East Germany for women in dependent employment in 2010. Self-employed women earn less, indicating that they, instead of maximizing income, primarily choose self-employment to take advantage of the independence to combine work and family obligations.
} 
dicates that within female participant's households additional income exists and hence income of female participants is not necessarily important to assure household's livelihood. This hypothesis is in line with descriptive evidence showing that the majority of female participants lives together in one household with a partner with working income, and that the partner's average working income is much higher than the income earned by self-employed female participants.

\subsubsection{Impact on Fertility}

Existing evaluation studies show that participation in traditional ALMP programs improve employment prospects for women, however, simultaneously induce a reduction in fertility. Therefore, it is very important to consider not only employment outcomes but also the impact on fertility, when evaluating program effectiveness for women.

To assess the impact on fertility at the extensive margin, we consider the difference between female participants and non-participants in terms of the "share with at least one maternity or parental leave within our observation window" ranging from program start to 56 months later. Table 5 shows negative estimates with respect to this outcome variable, indicating reduced fertility due to program participation; except for SUS female participants in East Germany, where we find higher shares of female participants taking maternity or parental leave. Although the effects are not statistically significant, the point estimates might be significant in economic terms. To assess the impact, we calculate the \%-change in fertility between participants and matched non-participants by comparing the absolute share of female participants with at least one maternity or parental leave (as depicted in Table 4) to the estimated effect on this outcome. The resulting numbers are also depicted in Table 5. For the SUS case in West Germany and BA in West and East Germany, it can be seen that program participation reduces fertility at the extensive margin by $5-34 \%$ within our observation window. SUS female participants in East Germany experience an increase in fertility by $31 \%$. These changes are quite large, and we have to be cautious with interpretation, as the calculation relies on the point estimates which are not statistically significant.

However, setting-up a business is time consuming and it might be the case that female participants postpone fertility decisions during their start-up period, but that this difference compared to non-participants disappears over time. To test this hypothesis, Figure A.2 in the Appendix shows the shares of female participants (black bars) and matched non-participants (gray bars) entering maternity or parental leave in each month after program start to approximate the timing of fertility. In contrast to the static outcome variable "share with at least one maternity or parental leave within our observation window" as depicted in Table 5, this approach allows for multiple entries into maternity or parental leave per person so that it partly includes the intensive margin of fertility. Female participants in East Germany seem to postpone fertility. It can be seen that non-participants are more likely to enter maternity or parental leave (gray bars predominate) at the beginning of the observation window, while participants face higher probabilities (black bars predominate) later on. For the case of West Germany, we do not find supporting evidence 
for our hypothesis of postponed fertility within the observation window. Here, program participation leads to an overall reduction in fertility.

Given the partly negative impact of participation in SUS and BA on fertility, the question remains whether employment effects become insignificant if fertility is considered as important as employment. We see at the bottom of Table 5 that the total cumulated effect on the outcome variable "self-employed, regular employed or in maternity or parental leave" (which considers employment and fertility as a success) is almost identical to the pure employment effects (which considers only employment as a success) in the upper part of the Table. Therefore, the large and positive employment effects in the SUS and BA case are by far not outweighed by partly negative effects on fertility.

\subsection{Sensitivity Analysis}

After having presented strong positive effects for both programs, we now check the robustness of our results with respect to deviations from the identifying assumption. If participants and non-participants differ in terms of unobserved characteristics, the CIA has been violated and therefore our results are biased. Since it is not possible to test the CIA directly with non-experimental data, we follow a holistic approach as conducted by Caliendo and Künn (2011) to check the robustness of our results. Due to limited space, we briefly summarize the main findings of the sensitivity analysis here and provide a detailed discussion and presentation of the results in the Supplementary Appendix.

First of all, we apply larger and smaller values of the bandwidth parameter for the Kernel estimation and test a different matching algorithm (Radius-matching with a caliper of 0.1) in order to see whether this has an impact on the causal estimates. Compared to the main results, the effects on employment and income hardly change. As a second test, we estimate the effects for different sub-sets of the population where participants and non-participants are most comparable. Using different common support conditions leads to similar results for employment outcomes. However, income measures seem to be at least to some extent sensitive with respect to common support conditions. The third test, where we allow for time-invariant unobserved differences between participants and non-participants by implementing conditional difference-in-difference, confirms the finding using different common support conditions. While employment effects hardly change, the absolute effects on working income vary quite a bit - in particular for women in East Germany. As a last step, we apply an artificial test, i.e., the simulation approach as suggested by Ichino, Mealli, and Nannicini (2008), to figure out to which degree of unobserved heterogeneity our results are robust. Although results on "SUS vs. NP" seem to be more sensitive to unobserved heterogeneity compared to "BA vs. NP", the tests indicate overall that our results seem to be robust with respect to unobserved heterogeneity. 


\section{Conclusion}

Due to high preferences for flexible working hours and limited availability of those jobs, the re-integration of unemployed women is difficult. In addition, low female labor market participation might induce statistical and subjective discrimination by employers which makes the integration of unemployed women even more difficult. Given those female-specific labor market constraints, the question arises whether ALMP are appropriate to improve re-integration chances of unemployed women. As traditional ALMP programs, such as training, job search assistance, job creation schemes or wage subsidies, primarily focus on the integration in dependent employment where flexible working schemes are limited and aforementioned types of discrimination might exist, the effectiveness is likely to be somehow limited as well. The existing literature generally shows a greater labor market attachment of female participants, however, it simultaneously induces a reduction in fertility. As employment is as important as fertility from a societal perspective, traditional ALMP programs are overall ineffective (see Lechner and Wiehler, 2011). In this context, the idea of supporting unemployed women to become self-employed is more promising. Unemployed women start their own business, which is detached from labor demand restrictions and gives them more independence and flexibility in allocating their time to work and family.

As long-term evidence is missing on the effectiveness of start-up programs for unemployed women and the impact on fertility is completely unexamined, we use a combination of administrative and long-term survey data to close this research gap. In particular, we consider entries in two distinct start-up programs (SUS and BA) for unemployed individuals in Germany and follow these individuals up to 56 months after start-up. Within the descriptive analysis, we find $57-67 \%$ of female participants are self-employed 56 months after start-up, of which on average $90 \%$ were continuously self-employed. This indicates a high and persistent integration into self-employment. Moreover, we find high shares of married women with children among female participants suggesting that they probably use self-employment to reconcile work and family. Among those who failed, a significant share is employed subject to social security contribution, so that we observe a total labor market integration of $76-90 \%$. The results on further job creation suggests that the double dividend argument is also true for women.

The causal analysis, where we use propensity score matching methods to compare program participants with non-participants (other unemployed women), shows large and significant employment effects for female participants which are three to four times as large as estimated employment effects for traditional ALMP programs such as training or job creation schemes. This underlines the success of SUS and BA, which is most likely due to better compatibility of work and family in self-employment. However, the large employment effects do not lead to a clear increase in working income 56 months after startup. Therefore, it might be that women primarily opt for self-employment due to limited employment prospects in the regular labor market and not to maximize working income. Moreover, additional human capital accumulation due to more employment experience among female participants might take more time to translate also into a working income 
gain and the period of 56 months is too short. With respect to fertility, we find a partly negative impact of participation in SUS and BA on fertility whereby the impact is highest during the first months after start-up, e.g., due to the time-consuming founding period. Compared to traditional ALMP programs however, large and positive employment effects in case of SUS and BA are by far not outweighed by negative effects on fertility. It seems that after a time-intensive founding period, self-employment - in contrast to dependent employment - gives women more independence and flexibility in allocating their time to work and family, which in turn increases employment chances. 


\section{References}

Abadie, A., And G. Imbens (2008): "On the Failure of the Bootstrap for Matching Estimators," Econometrica, 76(6), 1537-1557.

Almeida, R., and E. Galasso (2010): "Jump-Starting Self-Employment? Evidence Among Welfare Participants in Argentina," World Development, 38(5), 742-755.

Altonji, J. G., and C. R. Pierret (2001): "Employer Learning and Statistical Discrimination," The Quarterly Journal of Economics, 116(1), 313-350.

Becker, G. S. (1971): The Economics of Discrimination. The University of Chigago Press, second edn.

Behaghel, L., B. Crépon, and T. Le Barbanchonz (2012): "Do Anonymous Resumes Make the Battlefield More Even? Evidence From a Randomized Field Experiment," Working Paper, CREST.

Bergemann, A., and G. van den Berg (2008): "Active Labor Market Policy Effects for Women in Europe: A Survey," Annales d'Economie et de Statistique, 91/92, 385-408.

Biewen, M., B. Fitzenberger, A. Osikominu, and M. Waller (2007): "Which Program for Whom? Evidence on the Comparative Effectiveness of Public Sponsored Training Programs in Germany," Discussion Paper 2885, IZA, Bonn.

Black, D., And J. Smith (2004): "How Robust is the Evidence on the Effects of the College Quality? Evidence from Matching," Journal of Econometrics, 121(1), 99-124.

Blanchflower, D., And A. Oswald (1998): "What Makes an Entrepreneur?," Journal of Labor Economics, 16, 26-60.

Bönte, W., And M. Jarosch (2011): "Gender Differences in Competitiveness, Risk Tolerance, and other Personality Traits: Do they contribute to the Gender Gap in Entrepreneurship?," Schumpeter Discussion Paper 2011-012.

Caliendo, M. (2009): "Start-up subsidies in East Germany: finally, a policy that works?," International Journal of Manpower, 30(7), 625-647.

Caliendo, M., J. Hogenacker, S. Künn, and F. Wiessner (2012): "Alte Idee, neues Programm: Der Gründungszuschuss als Nachfolger von Überbrückungsgeld und IchAG," Zeitschrift für Arbeitsmarktforschung, forthcoming.

Caliendo, M., and R. Hujer (2006): "The Microeconometric Estimation of Treatment Effects - An Overview," Allgemeines Statistisches Archiv, 90(1), 197-212.

Caliendo, M., R. Hujer, and S. Thomsen (2008): "The Employment Effects of Job Creation Schemes in Germany - A Microeconometric Evaluation," in Modelling and Evaluating Treatment Effects in Econometrics, ed. by D. L. Millimet, J. A. Smith, and E. Vytlacil, vol. 21 of Advances in Econometrics, pp. 381-428. Elsevier, Amsterdam.

Caliendo, M., and S. Künn (2011): "Start-Up Subsidies for the Unemployed: LongTerm Evidence and Effect Heterogeneity," Journal of Public Economics, 95(3-4), 311331.

Caliendo, M., And S. Kopeinig (2008): "Some Practical Guidance for the Implementation of Propensity Score Matching," Journal of Economic Surveys, 22(1), 31-72.

Caliendo, M., and A. KRitikos (2009): "Die reformierte Existenzgründungsförderung für Arbeitslose - Chancen und Risiken," Perspektiven der Wirtschaftspolitik, 10(2), 189213. 
(2010): "Start-Ups by the Unemployed: Characteristics, Survival and Direct Employment Effects," Small Business Economics, 35(1), 71-92.

Charles, K. K., J. Guryan, and J. Pan (2009): "Sexism and Women's Labor Market Outcomes," Working Paper, University of Chicago.

Cressy, R. (1996): "Are Business Startups Debt-Rationed?," The Economic Journal, 106(438), 1253-1270.

Crump, R., V. J. Hotz, G. W. Imbens, and O. A. Mitnik (2009): "Dealing with Limited Overlap in Estimation of Average Treatment Effects," Biometrika, 96(1), 187199.

Cueto, B., And J. Mato (2006): "An Analysis of Self-Employment Subsidies with Duration Models," Applied Economics, 38, 23-32.

Dickinson, D. L., AND R. L. OAXACA (2009): "Statistical Discrimination in Labor Markets: An Experimental Analysis," Southern Economic Journal, 76(1), 16-31.

Edwards, L. N., and E. Field-Hendrey (2002): "Home-Based Work and Women's Labor Force Decisions," Journal of Labor Economics, 20(1), 170-200.

Ehlers, T. B., AND K. MAin (1998): "Women and the False Promise of Microenterprise," Gender and Society, 12(4), 424-440.

European Commission (2008): Gender Mainstreaming of Employment Policies: A Comparative Review of Thirty European Countries. Office for Official Publications of the European Communities, Luxembourg.

Fitzenberger, B., O. Orlyanskaya, A. Osikominu, and M. Paul (2012): "Déjà Vu? Short-Term Training in Germany 1980-1992 and 2000-2003," forthcoming in: Empirical Economics.

Fritsch, M. (2008): "How does New Business Development Affect Regional Development? Introduction to the Special Issue," Small Business Economics, 30, 1-14.

Gelbach, J. B. (2002): "Public Schooling for Young Children and Maternal Labor Supply," American Economic Review, 92(1), 307-322.

Goldin, C., And C. Rouse (2000): "Orchestrating Impartiality: The Impact of "Blind" Auditions on Female Musicians," American Economic Review, 90(4), 715-741.

Heckman, J., H. Ichimura, J. Smith, and P. Todd (1998): "Characterizing Selection Bias Using Experimental Data," Econometrica, 66(5), 1017-1098.

Ichino, A., F. Mealli, and T. Nannicini (2008): "From Temporary Help Jobs to Permanent Employment: What Can We Learn From Matching Estimators and their Sensitivity," Journal of Applied Econometrics, 23, 305-327.

Imbens, G., And J. M. Wooldridge (2009): "Recent Developments in the Econometrics of Program Evaluation," Journal of Economic Literature, 47(1), 5-86.

Johansson, K. (2001): "Do Labor Market Programs Affect Labor Force Participation," Swedish Economic Policy Review, 8, 215-234.

Kelly, R., P. Lewis, C. Mulvey, and B. Dalzell (2002): "A Study to Better Assess the Outcomes in the New Enterprise Incentive Scheme: Report Prepared for the Department of Employment and Work Place Relations," , University of Western Australia, the Centre for Labour Market Research. 
Kluve, J., D. Card, M. Fertig, M. Góra, L. Jacobi, P. Jensen, R. Leetmaa, E. Nima, L. Patacchini, S. Schaffner, C. M. Schmid, B. van der KlaAuw, and A. Weber (2007): Active Labor Market Policies in Europe: Performance and Perspectives. Springer-Verlag, Berlin, Heidelberg.

Knight, F. H. (1921): Risk, Uncertainty, and Profit. Prentice Hall.

Krause, A., U. Rinne, and K. Zimmermann (2012): "Anonymous Job Applications of Fresh Ph.D. Economists," Economics Letters, 117(2), 441-444.

Lechner, M., And S. Wiehler (2011): "Kids or Courses? Gender Differences in the Effects of Active Labor Market Policies," Journal of Population Economics, 24(3), 783812.

Lechner, M., And C. Wunsch (2011): "Sensitivity of Matching-Based Program Evaluations to the Availability of Control Variables," Discussion Paper 5553, IZA.

Lefebvre, P., and P. Merrigan (2008): "Child-Care Policy and the Labor Supply of Mothers with Young Children: A Natural Experiment from Canada," Journal of Labor Economics, 26(3), 519-548.

Martin, P., and D. GrubB (2001): "What Works and for Whom: A Review of OECD Countries Experiences with Active Labour Market Policies," Swedish Economic Policy Review, 8, 9-56.

Meager, N. (1996): "From Unemployement to Self-employement: Labour Market Policies for Business Start-up," in International Handbook of Labour Market Policy and Evaluation, ed. by G. Schmidt, J. O'Reilly, and K. Schömann, pp. 489-519. Edward Elgar.

Müller, P., And B. Kurtz (2003): "Active Labour Market Policy and Gender Mainstreaming in Germany," IAB Labour Market Research Topics 50, IAB.

Nannicini, T. (2007): "A Simulation-Based Sensitivity Analysis for Matching Estimators," Stata Journal, 7(3), 334-350.

Neumark, D., R. J. Bank, and K. D. VAn Nort (1996): "Sex Discrimination in Restaurant Hiring: An Audit Study," The Quarterly Journal of Economics, 111(3), 915-941.

O'Leary, C. J. (1999): "Promoting Self Employment Among the Unemployed in Hungary and Poland," Working Paper, W.E. Upjohn Institute for Employment Research.

PARker, S. C. (2009): The Economics of Entrepreneurship. Cambridge University Press, New York, Cambridge.

Perry, G. (2006): "Are Business Start-Up Subsidies Effective for the Unemployed: Evaluation of Enterprise Allowance," Working paper, Auckland University of Technology.

Phelps, E. S. (1972): "The Statistical Theory of Racism and Sexism," The American Economic Review, 62(4), 659-661.

Rosenbaum, P. R., and D. Rubin (1983): "The Central Role of the Propensity Score in Observational Studies for Causal Effects," Biometrika, 70(1), 41-50.

Roy, A. (1951): "Some Thoughts on the Distribution of Earnings," Oxford Economic Papers, 3(2), 135-145.

Rubery, J. (2002): "Gender Mainstreaming and European Employment Policy," in Labour Markets, Gender, and Institutional Change, ed. by H. Mosley, J. O'Reilly, and K. Schönmann. Cheltenham, UK/Northhampton, MA, USA. 
Rubin, D. (1974): "Estimating Causal Effects to Treatments in Randomised and Nonrandomised Studies," Journal of Educational Psychology, 66, 688-701.

Schone, P. (2004): "Labour Supply Effects of a Cash-for-Care Subsidy," Journal of Population Economics, 17(4), 703-727.

SiAnESI, B. (2004): "An Evaluation of the Swedish System of Active Labour Market Programmes in the 1990s," The Review of Economics and Statistics, 86(1), 133-155.

Sleebos, J. E. (2003): "Low Fertility Rates in OECD Countries: Facts and Policy Responses," OECD Social, Employment and Migration Working Papers 15.

Smith, J., And P. Todd (2005): "Does Matching Overcome LaLonde's Critique of Nonexperimental Estimators?," Journal of Econometrics, 125(1-2), 305-353.

Storey, D. (1994): Understanding the Small Business Sector. Routledge, London.

Whiteford, P., and W. Adema (2007): "What Works Best in Reducing Child Poverty: A Benefit or Work Strategy?," Social, Employment and Migration Working Papers 51, OECD.

Wooldridge, J. M. (2002): Econometric Analysis of Cross Section and Panel Data. The MIT Press. 


\section{Tables and Figures - Text}

Table 1: Entries into Selected ALMP Programs in Germany

\begin{tabular}{lrrrrrr}
\hline \hline & \multicolumn{2}{c}{2003} & \multicolumn{2}{c}{2005} & \multicolumn{2}{c}{2008} \\
& Women & Men & Women & Men & Women & Men \\
& & & & & & \\
& 131.3 & 163.4 & 61.5 & 91.3 & 219.6 & 265.8 \\
Vocational training & 54.8 & 86.2 & 29.7 & 48.4 & 28.5 & 41.7 \\
Job creation schemes & 453.2 & 613.5 & 379.4 & 521.9 & 549.9 & 664.6 \\
Short-term training & 71.4 & 112.0 & 50.4 & 92.3 & 108.5 & 173.0 \\
Wage subsidy & & & & & & \\
Promotion of self-employment & 41.3 & 117.4 & 43.0 & 113.9 & - & - \\
$\quad$ Bridging allowance & 38.9 & 56.3 & 43.8 & 47.2 & - & - \\
$\quad$ Start-up subsidy & - & - & - & - & 43.9 & 75.4 \\
$\quad$ New start-up subsidy & - & & & & & \\
\hline
\end{tabular}

Source: Statistics of the Federal Employment Agency, December 2010.

Notes: Numbers in thousand.

Table 2: Number of Observation at the Third Interview

\begin{tabular}{lrrrr}
\hline \hline & \multicolumn{3}{c}{ West Germany } & \multicolumn{2}{c}{$\begin{array}{c}\text { East Germany } \\
\text { Women }\end{array}$} & Men & Women & Men \\
& & & & \\
& 448 & 486 & 186 & 231 \\
Start-up subsidy recipients & 231 & 780 & 136 & 319 \\
Bridging allowance recipients & 591 & 929 & 271 & 423 \\
Non-participants & & & & \\
\hline
\end{tabular}

Notes: The third interview took place in May/June 2008, that is 56 months after business start-up. 
Table 3: Descriptive Statistics for Female Participants at Business Start-Up

\begin{tabular}{|c|c|c|c|c|}
\hline & \multicolumn{2}{|c|}{ Start-up Subsidy } & \multicolumn{2}{|c|}{ Bridging Allowance } \\
\hline & $\begin{array}{l}\text { West } \\
\text { Germany }\end{array}$ & $\begin{array}{c}\text { East } \\
\text { Germany }\end{array}$ & $\begin{array}{l}\text { West } \\
\text { Germany }\end{array}$ & $\begin{array}{c}\text { East } \\
\text { Germany }\end{array}$ \\
\hline \multicolumn{5}{|l|}{ A) Individual characteristics } \\
\hline Age (in years) & 39.1 & 40.9 & 38.2 & 40.4 \\
\hline Married & 55.7 & 69.5 & 37.1 & 64.4 \\
\hline At least one child & 49.2 & 46.4 & 24.7 & 46.8 \\
\hline Non-German & 29.6 & 38.0 & 26.0 & 31.7 \\
\hline Daily unemployment benefit level (in €) & 17.5 & 16.1 & 29.0 & 26.0 \\
\hline \multicolumn{5}{|l|}{ School leaving certificate } \\
\hline None or lower secondary degree & 31.0 & 13.9 & 17.3 & 6.1 \\
\hline Middle secondary degree & 33.5 & 55.9 & 24.7 & 47.7 \\
\hline Specialized and upper secondary school & 36.4 & 30.2 & 58.0 & 49.2 \\
\hline \multicolumn{5}{|l|}{ Intergenerational transmission } \\
\hline Parents are/were self-employed & 27.9 & 27.2 & 25.5 & 22.5 \\
\hline General willingness to take risk $^{a}$ ) & 5.4 & 5.5 & 5.7 & 5.8 \\
\hline \multicolumn{5}{|l|}{ B) Founding process } \\
\hline \multicolumn{5}{|l|}{ Motivation to become self-employed } \\
\hline I always wanted to be my own boss & 45.6 & 43.2 & 50.1 & 51.6 \\
\hline Termination of unemployment & 84.7 & 82.3 & 75.0 & 80.3 \\
\hline Capital invested at start-up $<€ 1,000$ & 69.3 & 60.9 & 43.7 & 46.8 \\
\hline Subsidy was highly relevant for start-up & 35.6 & 41.7 & 23.7 & 27.8 \\
\hline
\end{tabular}

Notes: All numbers are percentages unless otherwise indicated. A comparison to female nonparticipants and male participants can be found in Table A.1 in the Appendix.

a) Measured at the second interview, i.e., 28 months after start-up. Scale: $0=$ complete unwillingness; $10=$ complete willingness. 


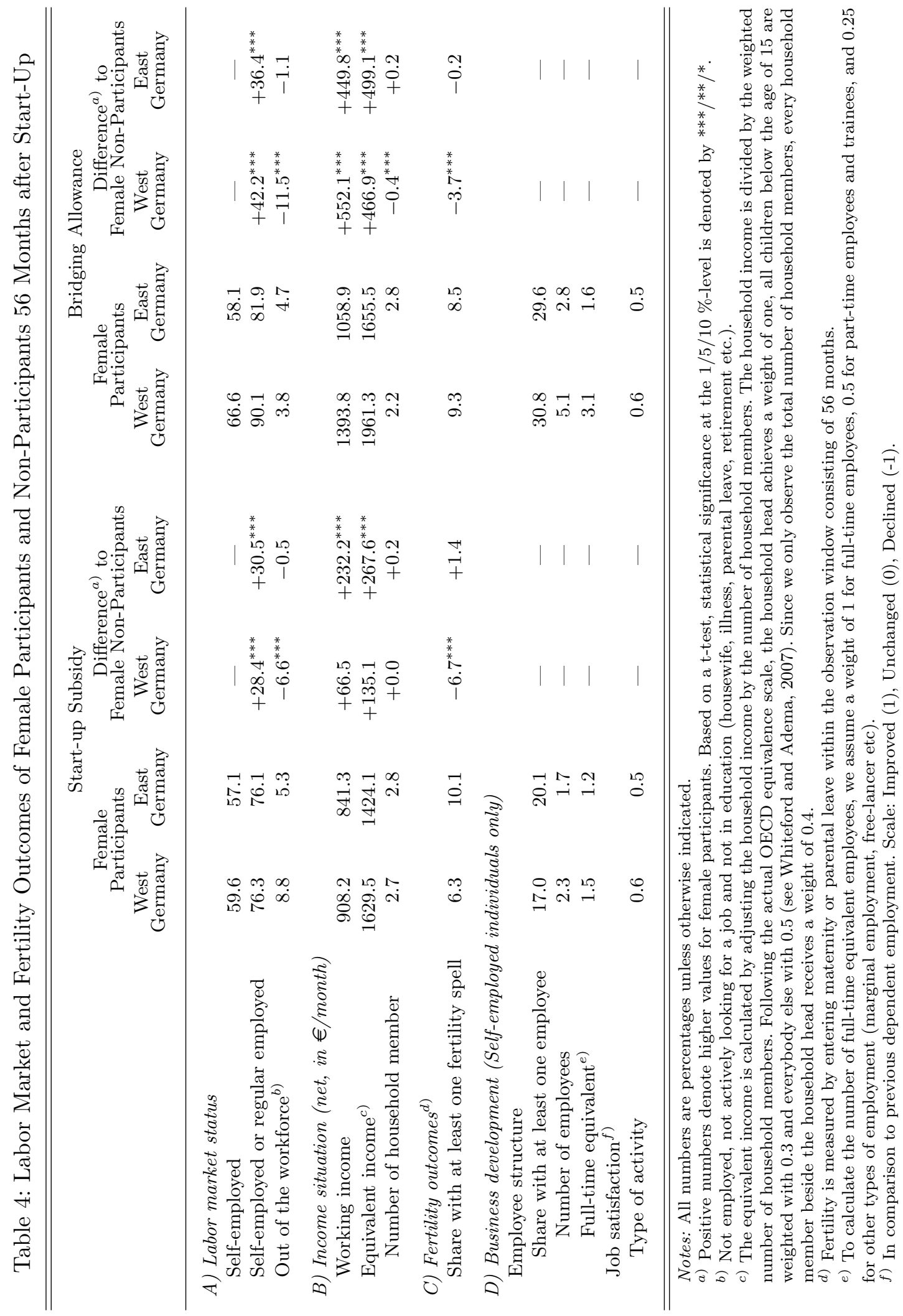


Table 5: Causal Effects of Start-up Subsidy and Bridging Allowance on Labor Market Outcomes and Fertility for Female Participants

\begin{tabular}{|c|c|c|c|c|}
\hline & \multicolumn{2}{|c|}{$\begin{array}{l}\text { Start-up Subsidy vs. } \\
\text { Non-Participation }\end{array}$} & \multicolumn{2}{|c|}{$\begin{array}{l}\text { Bridging Allowance vs } \\
\text { Non-Participation }\end{array}$} \\
\hline & $\begin{array}{l}\text { West } \\
\text { Germany }\end{array}$ & $\begin{array}{l}\text { East } \\
\text { Germany }\end{array}$ & $\begin{array}{l}\text { West } \\
\text { Germany }\end{array}$ & $\begin{array}{c}\text { East } \\
\text { Germany }\end{array}$ \\
\hline \multicolumn{5}{|l|}{ Number of observation } \\
\hline Treated & 413 & 173 & 225 & 128 \\
\hline Controls & 525 & 250 & 518 & 250 \\
\hline \multicolumn{5}{|l|}{ Self-employed or regular employed } \\
\hline Effect after 56 months & $\begin{array}{l}25.5^{* * *} \\
(3.5)\end{array}$ & $\begin{array}{l}37.8^{* * *} \\
(5.7)\end{array}$ & $\begin{array}{l}23.2^{* * *} \\
(3.9)\end{array}$ & $\begin{array}{l}33.1^{* * *} \\
(4.7)\end{array}$ \\
\hline Total cumulated effect $\left(\sum_{t=1}^{56}\right.$, in months $)$ & $\begin{array}{l}26.9^{* * *} \\
(1.4)\end{array}$ & $\begin{array}{l}29.8^{* * *} \\
(2.7)\end{array}$ & $\begin{array}{l}20.6^{* * *} \\
(1.7)\end{array}$ & $\begin{array}{l}25.9^{* * *} \\
(2.1)\end{array}$ \\
\hline \multicolumn{5}{|l|}{ Income measures } \\
\hline Monthly working income & $\begin{array}{l}138 \\
(84)\end{array}$ & $\begin{array}{c}348^{* * *} \\
(105)\end{array}$ & $\begin{array}{c}225 \\
(137)\end{array}$ & $\begin{array}{c}334^{* * *} \\
(100)\end{array}$ \\
\hline Monthly equivalent income ${ }^{a}$ ) & $\begin{array}{c}193^{* *} \\
(80)\end{array}$ & $\begin{array}{l}354^{* *} \\
(144)\end{array}$ & $\begin{array}{c}385^{* * *} \\
(118)\end{array}$ & $\begin{array}{c}357^{* * *} \\
(84)\end{array}$ \\
\hline \multicolumn{5}{|c|}{ Conditional analysis: Only full- or part-time employed individuals ( $\geq 15$ hours/week) } \\
\hline Monthly working income & $\begin{array}{l}-106 \\
(130)\end{array}$ & $\begin{array}{c}74 \\
(165)\end{array}$ & $\begin{array}{c}21 \\
(156)\end{array}$ & $\begin{array}{c}78 \\
(139)\end{array}$ \\
\hline \multicolumn{5}{|c|}{ Share with at least one maternity or parental leave within the observation window } \\
\hline Total effect within month 1-56 & $\begin{array}{c}-3.3 \\
(2.1)\end{array}$ & $\begin{array}{c}2.4 \\
(3.3)\end{array}$ & $\begin{array}{c}-4.4 \\
(3.5)\end{array}$ & $\begin{array}{c}-0.4 \\
(3.1)\end{array}$ \\
\hline Corresponding \%-change in fertility ${ }^{a}$ & -34.4 & +31.2 & -32.1 & -4.5 \\
\hline \multicolumn{5}{|c|}{ Self-employed, regular employed or in maternity or parental leave } \\
\hline Total cumulated effect $\left(\sum_{t=1}^{56}\right.$, in months $)$ & $\begin{array}{l}25.9^{* * *} \\
(1.3)\end{array}$ & $\begin{array}{l}29.6^{* * *} \\
(2.5)\end{array}$ & $\begin{array}{l}19.7^{* * *} \\
(1.8)\end{array}$ & $\begin{array}{l}25.0^{* * *} \\
(2.2)\end{array}$ \\
\hline
\end{tabular}

Notes: Depicted are average treatment effects on the treated as the difference in outcome variables between participants and non-participants. Standard errors are reported in parentheses and are based on bootstrapping with 200 replications. Statistical significance at the $1 / 5 / 10 \%$-level is denoted by $* * * / * * / *$.

Employment and fertility outcomes: Results are differences in \%-points unless otherwise stated.

Income measures: Results are differences in $€$ (net) measured 56 months after start-up and rely on a reduced sample size due to missing observation in income variables. To calculate hourly wages of individuals in dependent employment we consider actual (not contractual) working hours.

a) The calculation is based on a comparison of the affected "share" of female participants by maternity or parental leave (as shown in Table 4) with the estimated "effect" on this outcome. For instance, 6.3\% (share) of SUS participants in West Germany enter maternity or parental leave which is 3.3\%-points (effect) less than for matched non-participants. Therefore, fertility is reduced by $-34.4 \%(=3.3 /(6.3+3.3))$ for female participants. 


\section{A Appendix}

Table A.1: Descriptive Statistics for Female Participants at Business Start-up in Comparison to Female Non-Participants and Male Participants

\begin{tabular}{|c|c|c|c|c|c|c|}
\hline & \multicolumn{2}{|c|}{$\begin{array}{c}\text { Female } \\
\text { Participants }\end{array}$} & \multicolumn{2}{|c|}{$\begin{array}{l}\text { Difference }{ }^{a)} \text { to } \\
\text { Female Non-Participants }\end{array}$} & \multicolumn{2}{|c|}{$\begin{array}{l}\text { Difference }^{a)} \text { to } \\
\text { Male Participants }\end{array}$} \\
\hline & $\begin{array}{l}\text { West } \\
\text { Germany }\end{array}$ & $\begin{array}{c}\text { East } \\
\text { Germany }\end{array}$ & $\begin{array}{l}\text { West } \\
\text { Germany }\end{array}$ & $\begin{array}{l}\text { East } \\
\text { Germany }\end{array}$ & $\begin{array}{l}\text { West } \\
\text { Germany }\end{array}$ & $\begin{array}{c}\text { East } \\
\text { Germany }\end{array}$ \\
\hline & \multicolumn{6}{|c|}{ Start-up Subsidy } \\
\hline \multicolumn{7}{|l|}{ A) Individual characteristics } \\
\hline Age (in years) & 39.1 & 40.9 & -0.0 & +0.4 & $+1.8^{*}$ & +1.3 \\
\hline Married & 55.7 & 69.5 & +2.0 & +6.0 & $+11.4^{* * *}$ & $+10.1^{* *}$ \\
\hline At least one child & 49.2 & 46.4 & +4.0 & -2.9 & $+23.7^{* * *}$ & $+10.5^{* *}$ \\
\hline Non-German & 29.6 & 38.0 & +0.5 & +0.4 & -6.1 & $+9.8^{*}$ \\
\hline Daily unemployment benefit level (in €) & 17.5 & 16.1 & $-4.0^{* * *}$ & $-3.6^{* * *}$ & $-6.1^{* * *}$ & $-5.3^{* * *}$ \\
\hline \multicolumn{7}{|l|}{ School leaving certificate } \\
\hline None or lower secondary degree & 31.0 & 13.9 & +3.2 & $+5.6^{*}$ & $-18.8^{* * *}$ & -2.6 \\
\hline Middle secondary degree & 33.5 & 55.9 & +0.8 & -5.7 & $+9.8^{* * *}$ & -3.5 \\
\hline Specialized and upper secondary school & 36.4 & 30.2 & -4.8 & -1.4 & $+10.0^{* * *}$ & +5.2 \\
\hline \multicolumn{7}{|l|}{ Intergenerational transmission } \\
\hline Parents are/were self-employed & 27.9 & 27.2 & +4.9 & $+13.4^{* * *}$ & -1.6 & $+8.1^{*}$ \\
\hline General willingness to take risk $\left.{ }^{b}\right)$ & 5.4 & 5.5 & +0.3 & +0.2 & $-0.4^{*}$ & -0.3 \\
\hline \multicolumn{7}{|l|}{ B) Founding process } \\
\hline \multicolumn{7}{|l|}{ Motivation to become self-employed } \\
\hline I always wanted to be my own boss & 45.6 & 43.2 & - & - & $-9.0^{* *}$ & -7.4 \\
\hline Termination of unemployment & 84.7 & 82.3 & - & - & +1.3 & -3.6 \\
\hline Capital invested at start-up $<€ 1,000$ & 69.3 & 60.9 & - & - & $+13.6^{* * *}$ & $+11.6^{* *}$ \\
\hline \multirow[t]{2}{*}{ Subsidy was highly relevant for start-up } & 35.6 & 41.7 & - & - & +5.2 & +7.2 \\
\hline & \multicolumn{6}{|c|}{ Bridging Allowance } \\
\hline \multicolumn{7}{|l|}{ A) Individual characteristics } \\
\hline Age (in years) & 38.2 & 40.4 & -0.9 & -0.0 & -0.5 & +2.1 \\
\hline Married & 37.1 & 64.4 & $-16.6^{* * *}$ & +0.8 & $-23.2^{* * *}$ & +5.7 \\
\hline At least one child & 24.7 & 46.8 & $-20.5^{* * *}$ & -2.5 & $-12.9^{* * *}$ & $+12.1^{* *}$ \\
\hline Non-German & 26.0 & 31.7 & -3.1 & -5.8 & -3.2 & $+12.1^{* * *}$ \\
\hline Daily unemployment benefit level (in €) & 29.0 & 26.0 & $+7.5^{* * *}$ & $+6.3^{* * *}$ & $-9.4^{* * *}$ & $-3.4^{* *}$ \\
\hline \multicolumn{7}{|l|}{ School leaving certificate } \\
\hline None or lower secondary degree & 17.3 & 6.1 & $-10.6^{* *}$ & -2.2 & $-17.8^{* * *}$ & -5.3 \\
\hline Middle secondary degree & 24.7 & 47.7 & $-8.0^{* *}$ & $-13.9^{* *}$ & +1.0 & $-10.7^{*}$ \\
\hline Specialized and upper secondary school & 58.0 & 49.2 & $+16.9^{* * *}$ & $+17.6^{* * *}$ & $+16.7^{* * *}$ & $+18.1^{* * *}$ \\
\hline \multicolumn{7}{|l|}{ Intergenerational transmission } \\
\hline Parents are/were self-employed & 25.5 & 22.5 & +2.5 & $+8.6^{* *}$ & -3.3 & -3.5 \\
\hline General willingness to take risk $^{b)}$ & 5.7 & 5.8 & $+0.6^{* *}$ & $+0.5^{*}$ & -0.2 & +0.2 \\
\hline \multicolumn{7}{|l|}{ B) Founding process } \\
\hline \multicolumn{7}{|l|}{ Motivation to become self-employed } \\
\hline I always wanted to be my own boss & 50.1 & 51.6 & - & - & -5.8 & -3.6 \\
\hline Termination of unemployment & 75.0 & 80.3 & - & - & -1.7 & +4.4 \\
\hline Capital invested at start-up $<€ 1,000$ & 43.7 & 46.8 & - & - & $+9.1^{* *}$ & $+15.6^{* * *}$ \\
\hline Subsidy was highly relevant for start-up & 23.7 & 27.8 & - & - & -0.1 & +2.9 \\
\hline
\end{tabular}

Notes: All numbers are percentages unless otherwise indicated.

a) Positive numbers denote higher values for female participants. Based on a t-test, statistical significance at the $1 / 5 / 10 \%$-level is denoted by $* * * / * * / *$.

b) Measured at the second interview, i.e., 28 months after start-up. Scale: $0=$ complete unwillingness; $10=$ complete willingness. 
Table A.2: Propensity Score Estimation: Female Participants vs. Non-Participation

\begin{tabular}{|c|c|c|c|c|}
\hline & \multicolumn{2}{|c|}{ Start-up Subsidy } & \multicolumn{2}{|c|}{ Bridging Allowance } \\
\hline & $\begin{array}{l}\text { West } \\
\text { Germany }\end{array}$ & $\begin{array}{c}\text { East } \\
\text { Germany }\end{array}$ & $\begin{array}{c}\text { West } \\
\text { Germany }\end{array}$ & $\begin{array}{c}\text { East } \\
\text { Germany }\end{array}$ \\
\hline \multicolumn{5}{|l|}{ Age bracket (Ref.: 18 to 24 years) } \\
\hline 25 to 29 years & $0.677^{* *}$ & -.358 & 0.117 & -.213 \\
\hline 30 to 34 years & 0.466 & -.318 & 0.387 & -.142 \\
\hline 35 to 39 years & 0.484 & -.019 & 0.449 & -.083 \\
\hline 40 to 44 years & $0.671^{* *}$ & -.215 & $0.623^{*}$ & -.130 \\
\hline 45 to 49 years & $0.631^{*}$ & 0.038 & 0.538 & -.132 \\
\hline 50 to 64 years & $0.803^{* *}$ & 0.008 & $0.794^{* *}$ & -.340 \\
\hline \multicolumn{5}{|l|}{ Marital status (Ref.: Single) } \\
\hline Married & 0.014 & 0.132 & -.155 & -.001 \\
\hline \multicolumn{5}{|l|}{ Number of children in household (Ref.: No children) } \\
\hline One child & -.020 & -.118 & 0.063 & -.099 \\
\hline Two or more children & -.158 & -.118 & -.130 & -.010 \\
\hline \multicolumn{5}{|l|}{ Health restriction that affect job placement (Ref.: No) } \\
\hline Yes & -.026 & $-1.099^{* *}$ & 0.363 & 0.046 \\
\hline \multicolumn{5}{|l|}{ Nationality (Ref.: German) } \\
\hline Non-German & -.043 & 0.087 & -.171 & 0.059 \\
\hline \multicolumn{5}{|l|}{ Desired working time (Ref.: Part-time) } \\
\hline Full-time & -.036 & 0.084 & $0.499^{* * *}$ & 0.129 \\
\hline \multicolumn{5}{|l|}{ School achievement (Ref.: None) } \\
\hline Lower secondary school & 0.304 & & -.454 & \\
\hline Middle secondary school & 0.399 & -.255 & -.159 & 0.052 \\
\hline Specialized upper secondary school & 0.239 & -.045 & -.158 & 0.091 \\
\hline Upper secondary school & 0.388 & -.029 & -.329 & 0.135 \\
\hline \multicolumn{5}{|l|}{ Occupational group (Ref.: Manufacturing) } \\
\hline Agriculture & -.153 & -.407 & 0.671 & 0.025 \\
\hline Technical occupations & 0.115 & 0.614 & 0.654 & 0.466 \\
\hline Services & -.238 & 0.140 & 0.703 & 0.232 \\
\hline Others & -.443 & 0.150 & 0.376 & 0.145 \\
\hline \multicolumn{5}{|c|}{ Professional qualification (Ref.: Workers with tertiary education) } \\
\hline Workers with technical college education & -.102 & 0.146 & 0.171 & 0.028 \\
\hline Skilled workers & -.197 & 0.407 & -.138 & 0.097 \\
\hline Unskilled workers & -.019 & 0.532 & -.252 & 0.125 \\
\hline \multicolumn{5}{|l|}{ Duration of previous unemployment (Ref.: $<1$ month) } \\
\hline$\geq 1$ month -3 months & $-1.427^{* * *}$ & $-2.089^{* * *}$ & $-1.577^{* * *}$ & -.560 \\
\hline$\geq 3$ months $-<6$ months & $-1.904^{* * *}$ & $-1.822^{* * *}$ & $-1.812^{* * *}$ & -.526 \\
\hline$\geq 6$ months $-<1$ year & $-1.554^{* * *}$ & $-1.647^{* * *}$ & $-1.768^{* * *}$ & -.418 \\
\hline$\geq 1$ year $-<2$ years & $-1.682^{* * *}$ & $-1.814^{* * *}$ & $-1.897^{* * *}$ & -.407 \\
\hline$\geq 2$ years & $-1.456^{* * *}$ & $-1.176^{* *}$ & $-2.159^{* * *}$ & -.490 \\
\hline \multicolumn{5}{|l|}{ Professional experience (Ref.: Without professional experience) } \\
\hline with professional experience & 0.049 & 0.060 & -.145 & 0.032 \\
\hline Duration of last employment (in months) & 0.0002 & 0.003 & 0.002 & $0.003^{*}$ \\
\hline Number of placement offers & -.010 & $-.024^{*}$ & -.014 & -.006 \\
\hline Remaining unemployment benefit entitlement (in months) & $-.022^{* *}$ & -.022 & -.016 & -.010 \\
\hline Daily unemployment benefit level (in $€$ ) & $-.020^{* * *}$ & $-.022^{* *}$ & $0.023^{* * *}$ & -.003 \\
\hline \multicolumn{5}{|l|}{ Daily income from regular employment } \\
\hline in the first half of 2003 (in €) & $-.005^{*}$ & -.002 & -.004 & 0.001 \\
\hline \multicolumn{5}{|l|}{ Employment status before job-seeking (Ref.: Employment) } \\
\hline Self-employed & 0.212 & $0.821^{* *}$ & $-.748^{*}$ & -.254 \\
\hline
\end{tabular}


Table A.2 continued.

\begin{tabular}{|c|c|c|c|c|}
\hline & \multicolumn{2}{|c|}{ Start-up Subsidy } & \multicolumn{2}{|c|}{ Bridging Allowance } \\
\hline & $\begin{array}{c}\text { West } \\
\text { Germany }\end{array}$ & $\begin{array}{c}\text { East } \\
\text { Germany }\end{array}$ & $\begin{array}{l}\text { West } \\
\text { Germany }\end{array}$ & $\begin{array}{c}\text { East } \\
\text { Germany }\end{array}$ \\
\hline School attendance/never employed before/apprenticeship & 0.19 & -.100 & -.023 & -.032 \\
\hline Unemployable & 0.237 & $0.757^{* * *}$ & 0.07 & 0.097 \\
\hline Other, but at least once employed before & $0.344^{* *}$ & 0.011 & $0.415^{* *}$ & -.176 \\
\hline Other & -.343 & 0.371 & & 0.055 \\
\hline \multicolumn{5}{|l|}{ Regional cluster (Ref.: II a) } \\
\hline I a & & 0.030 & & -.296 \\
\hline $\mathrm{I} \mathrm{b}$ & & -.223 & & -.119 \\
\hline I c & & -.033 & & -.030 \\
\hline II b & 0.453 & & -.472 & \\
\hline III a & 0.299 & & $-.721^{* *}$ & \\
\hline III b & 0.495 & & -.416 & \\
\hline III c & 0.408 & & $-.889^{* * *}$ & \\
\hline IV & 0.46 & & -.390 & \\
\hline $\mathrm{V} \mathrm{a}$ & -.002 & & $-.981^{* *}$ & \\
\hline $\mathrm{V} b$ & 0.56 & & $-.627^{*}$ & \\
\hline $\mathrm{V} \mathrm{c}$ & 0.647 & & $-.759^{* *}$ & \\
\hline \multicolumn{5}{|l|}{ Intergenerational transmission } \\
\hline Parents are/were self-employed & $0.187^{*}$ & $0.550^{* * *}$ & 0.103 & -.044 \\
\hline Constant & 0.902 & $1.566^{* *}$ & 0.415 & $-.454^{* * *}$ \\
\hline \multicolumn{5}{|l|}{ Number of observations } \\
\hline Participants & 438 & 183 & 228 & 135 \\
\hline Non-participants & 525 & 250 & 518 & 250 \\
\hline Hit-Rate (share of correct predictions in \%) & 64.07 & 68.59 & 68.13 & 68.31 \\
\hline Pseudo $\mathrm{R}^{2}$ & 0.121 & 0.187 & 0.181 & 0.041 \\
\hline Log-likelihood & -583.361 & -239.643 & -376.267 & -239.205 \\
\hline
\end{tabular}

Notes: Statistical significance at the $1 / 5 / 10 \%$-level is denoted by $* * * / * * / *$. 
Figure A.1: Propensity Score Distributions: Participation vs. Non-Participation

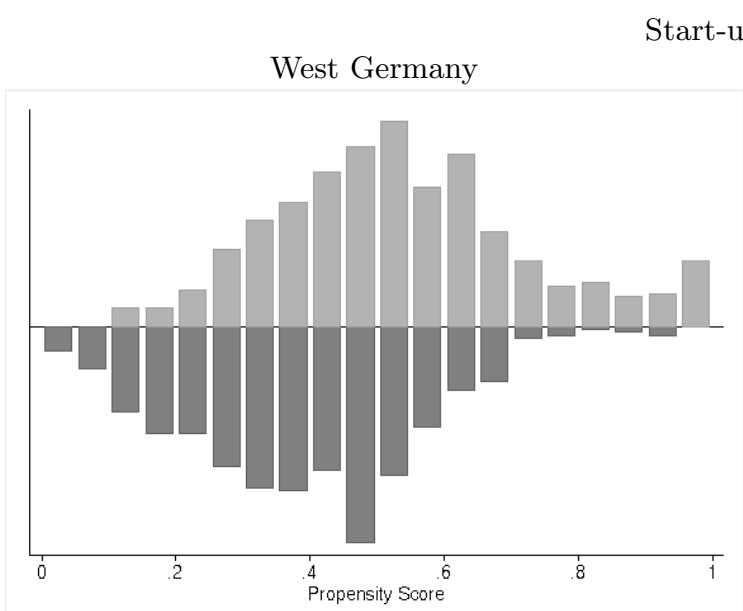

East Germany

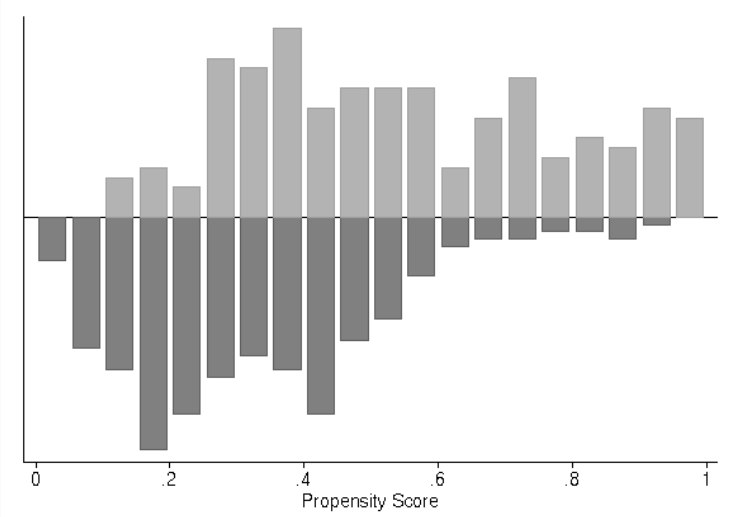

Bridging Allowance

West Germany

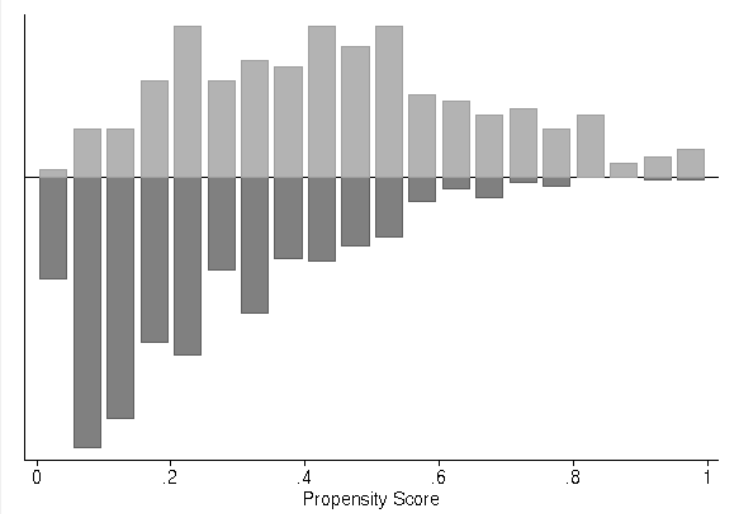

Participants
East Germany

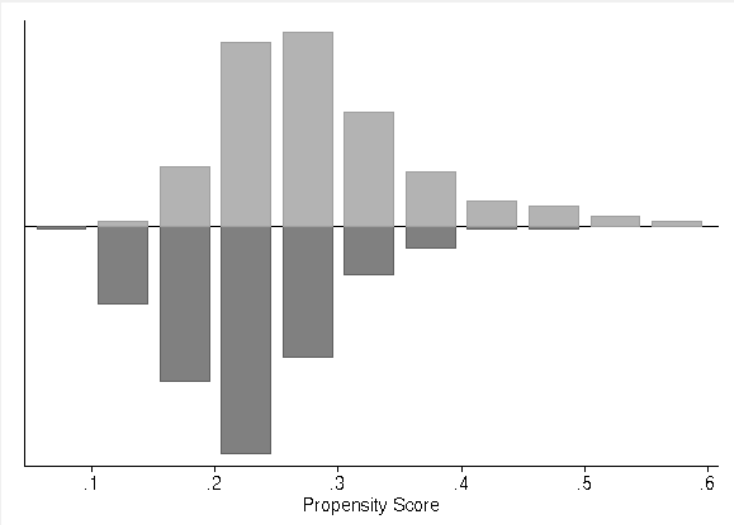

Non-Participants

Notes: These are propensity score distributions for female participants and non-participants based on estimations in Table A.2. 
Table A.3: Matching Quality

\begin{tabular}{|c|c|c|c|c|c|}
\hline & & \multicolumn{2}{|c|}{$\begin{array}{l}\text { Start-up Subsidy vs. } \\
\text { Non-Participation }\end{array}$} & \multicolumn{2}{|c|}{$\begin{array}{l}\text { Bridging Allowance vs. } \\
\text { Non-Participation }\end{array}$} \\
\hline & & West Germany & East Germany & West Germany & East Germany \\
\hline Number of variables & & 56 & 50 & 55 & 50 \\
\hline \multicolumn{6}{|l|}{ t-test of equal means ${ }^{a}$ ) } \\
\hline \multirow[t]{2}{*}{$1 \%$-level } & unmatch & 6 & 8 & 9 & 4 \\
\hline & match & 1 & 0 & 0 & 2 \\
\hline \multirow[t]{2}{*}{$5 \%$-level } & unmatch & 11 & 13 & 17 & 14 \\
\hline & match & 1 & 1 & 1 & 4 \\
\hline \multirow[t]{2}{*}{$10 \%$-level } & unmatch & 16 & 13 & 21 & 18 \\
\hline & match & 1 & 1 & 1 & 6 \\
\hline \multicolumn{6}{|l|}{ Standardized bias } \\
\hline \multirow[t]{2}{*}{ Mean standardized bias } & unmatch & 9.354 & 11.816 & 13.606 & 13.928 \\
\hline & match & 2.694 & 6.549 & 3.738 & 8.289 \\
\hline \multicolumn{6}{|c|}{ Number of variables with standardized bias of a certain amount } \\
\hline \multirow[t]{2}{*}{$<1 \%$} & unmatch & 5 & 4 & 2 & 3 \\
\hline & match & 18 & 2 & 11 & 3 \\
\hline \multirow[t]{2}{*}{$1 \%$ until $<3 \%$} & unmatch & 9 & 6 & 7 & 3 \\
\hline & match & 20 & 5 & 14 & 11 \\
\hline \multirow[t]{2}{*}{$3 \%$ until $<5 \%$} & unmatch & 4 & 6 & 8 & 6 \\
\hline & match & 8 & 13 & 15 & 6 \\
\hline \multirow[t]{2}{*}{$5 \%$ until $<10 \%$} & unmatch & 20 & 13 & 9 & 13 \\
\hline & match & 9 & 21 & 14 & 16 \\
\hline \multirow[t]{2}{*}{$\geq 10 \%$} & unmatch & 18 & 21 & 29 & 25 \\
\hline & match & 1 & 9 & 1 & 14 \\
\hline \multirow[t]{2}{*}{ Pseudo $\mathrm{R}^{2}$} & unmatch & 0.120 & 0.187 & 0.181 & 0.021 \\
\hline & match & 0.009 & 0.034 & 0.019 & 0.001 \\
\hline
\end{tabular}

Notes: Depicted are different statistics to assess the quality of the matching process, i.e., whether the distribution of observable characteristics between female participants and non-participants is sufficiently balanced. Deviant values in terms of Pseudo $\mathrm{R}^{2}$ compared to Table A.2 are due to implemented common support conditions, i.e., due to excluded observations.

a) Depicted is the number of variables which differ significantly between treated and controls. The decision is based on a simple t-test of equal means. 
Figure A.2: Distribution of Entries into Maternity or Parental Leave Across Female Participants and Matched Non-Participants Over Time

Start-up Subsidy

West Germany

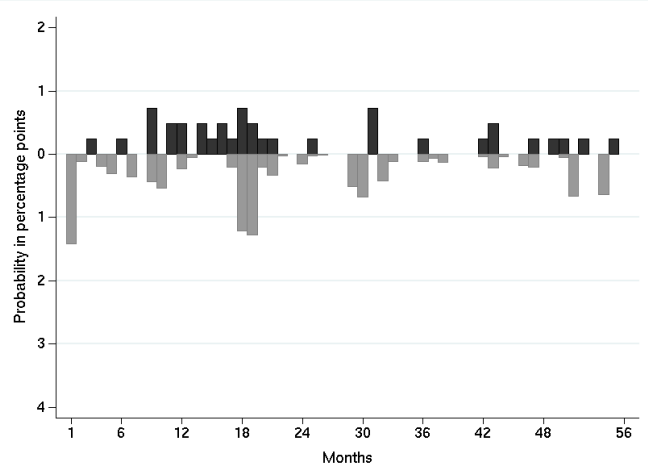

East Germany

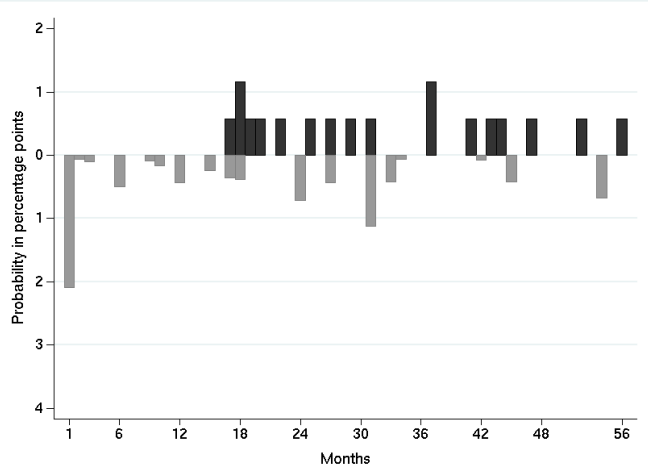

Bridging Allowance

West Germany

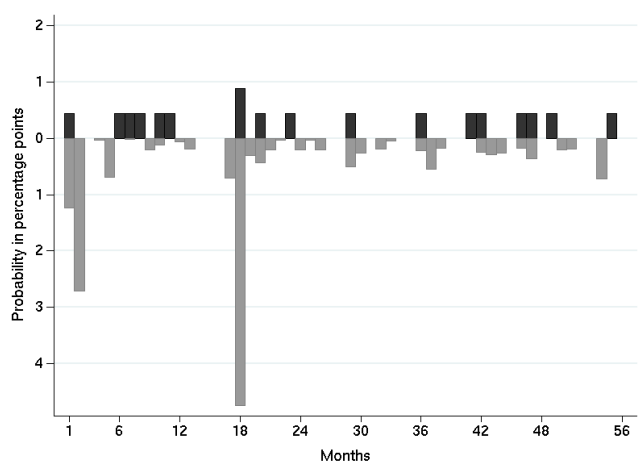

Participants

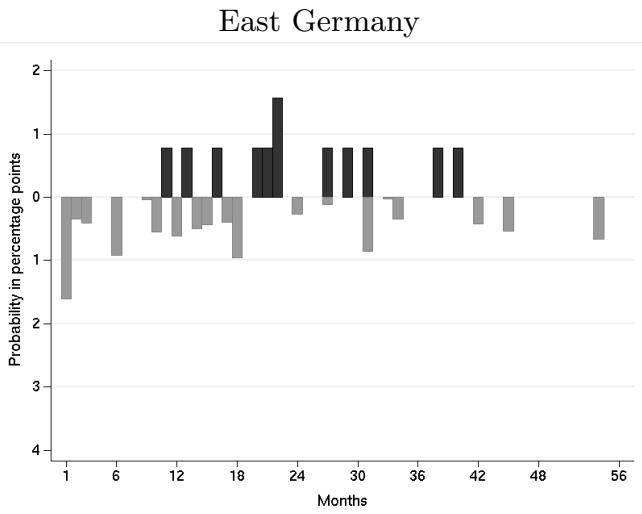

Matched non-participants

Notes: The graphs show the share of female participants and matched non-participants entering maternity or parental leave in each month; multiple entries per individual are allowed. 


\section{B Supplementary Appendix: Sensitivity Analysis}

This supplementary appendix contains detailed information to the sensitivity analysis as presented in Section 5.4. We restrict the analysis and consider three outcome variables only, the cumulated effect on "self-employment or regular employment", the "working income" measured 56 months after start-up and the "share in maternity or parental leave within our observation window". The results hardly differ for other outcome variables and depicting only three of them eases clearly the exposition. ${ }^{1}$ The sensitivity analysis checks the robustness of our results in four directions: matching algorithm, common support condition, time-invariant unobserved heterogeneity (conditional difference-in-difference) and the potential influence of unobserved heterogeneity. Below we discuss each testing strategy in detail and summarize the estimated ATT using different estimation methods and common support conditions in Table B.1 and results of sensitivity test with respect to unobserved heterogeneity in Table B.2 where we concentrate on the effects on the outcome variable "self-employed or regular employed" after 56 months since start-up. To ease the comparison to our main results, both tables also contain the respective main results (from Table 5) at the top.

\section{Insert TABLE B.1 AND B.2 ABOUt HeRE}

\section{Alternative Matching Algorithm}

To estimate our main results, we apply Kernel-matching by using an Epanechnikov Kernel with a bandwidth of 0.06. However, the choice of the bandwidth parameter might significantly affect the results (Caliendo and Kopeinig, 2008). Using an Epanechnikov Kernel and increasing (decreasing) the bandwidth parameter has two consequences: First, more (less) control individuals are included and second, control individuals far away from the participant in terms of propensity scores receive higher (lower) weights. Therefore, the choice of the bandwidth parameter involves a trade-off between the preciseness of the estimate and its variance. We test the sensitivity of our results in this regard and apply a remarkably larger (smaller) bandwidth of 0.2 (0.02). Panel A in Table B.1 shows the estimated effects and we can see that our main results seem to be very robust with respect to the choice of the bandwidth parameter.

The advantage of using Kernel-matching is that all control observations are used to construct the counterfactual outcome which lowers the variance of the estimate. However, as mentioned by Caliendo and Kopeinig (2008), the advantage is a disadvantage at the same time as each participant will be matched to all non-participants even if those are actually bad matches. The distance in terms of propensity scores between participants and non-participants mirrors their comparability and using for each participant only controls who have close values of propensity scores might have an influence on our results. We therefore apply Radius-matching which uses for each participant only non-participants within a certain caliper. Using a caliper of $0.1^{2}$, Panel A in Table B.1 shows the estimated

\footnotetext{
${ }^{1}$ Results are available on request from the authors.

${ }^{2}$ Due to limited space we refrain from presenting results for different values of caliper; results hardly differ.
} 
effects. Compared to the main results, the effects on employment, income and fertility hardly change.

\section{Common Support Condition}

While Radius-matching only uses non-participants depending on the individual value of participant's propensity score, a different approach is to shrink the overall common support $^{3}$ in order to minimize the bias due to unobserved factors. Black and Smith (2004) show that a lingering selection on unobservables will have its largest effects on bias for values of the propensity score in the tails of the distribution. Matching estimators rely on the right tail of the distribution of propensity scores in the comparison group and therefore might be biased. To deal with this, we restrict the common support in three different ways. First, we adopt the approach by Black and Smith (2004), who estimate the effects only in a "thick support" region defined by $0.33<\hat{P}(W)<0.67$. Second, we divide the propensity score distribution into ten deciles and estimate the effects only in regions where we have a density of at least $5 \%$ in both groups (participants and non-participants) respectively. Third, following a more objective measure suggested by Crump, Hotz, Imbens, and Mitnik (2009), we restrict the analysis to a subset of the original sample by dropping individuals with propensity scores outside an optimal common support range $(\alpha<\hat{P}(W)<(1-\alpha))$ and estimate the optimal subpopulation average treatment effects (OSATE). The optimal cut-off point $\alpha$ is determined by balancing two opposing impacts on the variance term of the estimated effect: while the variance increases due to the smaller sample size, the variance also decreases as participants with covariate values outside the range of the nonparticipants are excluded. The results of all three approaches are available in Table B.1 (Panel B). It can be seen that the estimates based on stronger common support conditions are quite similar to our main results in terms of the employment outcome. In terms of working income and fertility, stronger variations are observable. However, the variations in absolute values do not change the overall significance of the results, with two exceptions of Thick support 1 for SUS (BA) female participants in East Germany with respect to fertility (working income). Although it is not clear whether the differences arise either from genuinely larger impacts in this region or lingering selection on unobservables, which plays a bigger role outside the thick support region than within it, we have to keep in mind that effects on income measures and fertility seem to be at least to some extent sensitive with respect to common support conditions.

\section{Conditional Difference-in-Difference}

We further test the sensitivity of the results with respect to time-invariant unobserved differences between participants and non-participants by implementing conditional differencein-differences (DID) which was initially suggested by Heckman et al. (1998). This allows for unobservable but temporally invariant differences in outcomes between participants and non-participants, which obviously relaxes the CIA. It extends the conventional DID

\footnotetext{
${ }^{3}$ Restricting the estimation sample in such a way lowers external validity of the estimate, but probably enhances internal validity (Imbens and Wooldridge, 2009).
} 
estimator by defining outcomes conditional on the propensity score and using semiparametric methods to construct the estimate. If the parameter of interest is ATT, it can be written as:

$$
\tau_{A T T}^{C D I D}=E\left(Y_{t}^{1}-Y_{t^{\prime}}^{0} \mid P(W), D=1\right)-E\left(Y_{t}^{0}-Y_{t^{\prime}}^{0} \mid P(W), D=0\right) .
$$

where $(t)$ is the post-treatment and $\left(t^{\prime}\right)$ the pre-treatment period.

Before using such an approach, one has to determine the reference level for the before/after difference. For the outcome variable "self-employed or regular employed", we choose three different time periods for the comparison. In the first approach (DID1) we use the time period from July 1998 to June 2003, i.e., the five-year employment history before entering the program. For the first outcome variable, we sum the months not spent in unemployment; whereas for the second, we sum the months spent in paid employment. In additional, we restrict the reference period to the latest 2.5 years (DID2, January 2001June 2003) as well as the earliest 2.5 years (DID3, July 1998 to December 2000). To construct the DID estimate with respect to working income, we use the average monthly income in 2002 as the reference level (DID4). We cannot provide estimates with respect to the fertility outcome using DID as we have no information on periods spend in maternity or parental leave for the pre-treatment period. The estimated values of $\tau_{A T T}^{C D I D}$ are depicted in Panel C in Table B.1. As we can see, the picture is quite similar to the results using different common support conditions. While employment effects hardly change, the absolute effects on working income vary quite a bit - in particular for women in East Germany.

\section{Tests on Unobserved Heterogeneity}

Using the DID estimator already relaxes the identifying assumption by allowing for timeinvariant unobservable differences between both groups. Since it is not possible to test the CIA directly with non-experimental data, we now use a simulation approach as suggested by Ichino, Mealli, and Nannicini (2008). This approach consists of simulating an unobserved component and testing to which degree of unobserved heterogeneity results are robust. To construct such an unobserved component, this approach simulates an unobserved confounder by adapting the distribution of an observable variable. Since we exactly know the influence of the observable characteristics on selection from the probit-estimation we have a direct linkage to the potential unobserved leverage for the interpretation. Note however, that this approach does not answers the question whether the CIA is fulfilled, but it conveys information on the robustness of the results with respect to unobserved heterogeneity. The resulting estimated values of $\tau_{A T T}^{M A T}$ given the existence of a confounder with a certain distribution are shown in Table B.1. The results are almost identical compared to those in the absence of unobserved heterogeneity. It has to be mentioned that for the case of BA this test is not as strong as for SUS as the confounders "duration of previous unemployment" (for East Germany) and "parental self-employment" (for East and West Germany) are not statistically significant in the probit-estimation (compare Table A.2). We conclude that the baseline effects seem to be robust with respect to unobserved heterogeneity. 
Table B.1: Sensitivity to Estimation Methods

\begin{tabular}{|c|c|c|c|c|}
\hline & \multicolumn{2}{|c|}{$\begin{array}{l}\text { Start-up Subsidy vs. } \\
\text { Non-Participation }\end{array}$} & \multicolumn{2}{|c|}{$\begin{array}{l}\text { Bridging Allowance vs. } \\
\text { Non-Participation }\end{array}$} \\
\hline & West Germany & East Germany & West Germany & East Germany \\
\hline \multicolumn{5}{|l|}{ Main results (compare Table 5) } \\
\hline $\mathrm{SE}$ or $\operatorname{RE}\left(\sum_{t=1}^{56}\right)$ & $26.9(1.4)$ & $29.8(2.7)$ & $20.6(1.7)$ & $25.9(2.1)$ \\
\hline Working income $(€ /$ month, $t=56)$ & $138(84)$ & $348(105)$ & $225(137)$ & $334(100)$ \\
\hline Fertility & $-3.3(2.1)$ & $2.4(3.3)$ & $-4.4(3.5)$ & $-0.4(3.1)$ \\
\hline \multicolumn{5}{|l|}{ A) Alternative matching procedure } \\
\hline \multicolumn{5}{|l|}{ Kernel-matching with a bandwidth of 0.02} \\
\hline $\mathrm{SE}$ or $\mathrm{RE}\left(\sum_{t=1}^{56}\right)$ & $27.2(1.3)$ & $28.3(2.3)$ & $21.2(1.7)$ & $26.6(2.1)$ \\
\hline Working income $(€ /$ month, $t=56)$ & $154(92)$ & $334(104)$ & $229(151)$ & $356(85)$ \\
\hline Fertility & $-3.2(2.0)$ & $0.6(3.5)$ & $-3.0(2.8)$ & $-0.2(3.9)$ \\
\hline \multicolumn{5}{|l|}{ Kernel-matching with a bandwidth of 0.2} \\
\hline $\mathrm{SE}$ or $\mathrm{RE}\left(\sum_{t=1}^{56}\right)$ & $26.8(1.3)$ & $29.5(2.3)$ & $21.9(1.6)$ & $26.3(2.0)$ \\
\hline Working income $(€ /$ month, $t=56)$ & $120(87)$ & $338(108)$ & $264(135)$ & $381(85)$ \\
\hline Fertility & $-3.1(2.0)$ & $1.7(3.0)$ & $-4.1(2.8)$ & $-1.1(3.0)$ \\
\hline \multicolumn{5}{|l|}{ Radius-matching with a caliper of 0.1} \\
\hline $\mathrm{SE}$ or $\mathrm{RE}\left(\sum_{t=1}^{56}\right)$ & $27.0(1.3)$ & $29.4(2.2)$ & $21.2(1.7)$ & $26.0(1.9)$ \\
\hline Working income $(€ /$ month, $t=56)$ & $137(84)$ & $339(118)$ & $235(133)$ & $356(93)$ \\
\hline Fertility & $-3.2(1.9)$ & $1.8(3.1)$ & $-4.6(3.0)$ & $-0.9(3.1)$ \\
\hline \multicolumn{5}{|l|}{ B) Common support condition } \\
\hline \multicolumn{5}{|l|}{ Thick support $1-0.33<\hat{P}(W)<0.67$} \\
\hline $\mathrm{SE}$ or $\mathrm{RE}\left(\sum_{t=1}^{56}\right)$ & $27.8(1.3)$ & $32.6(2.5)$ & $20.9(2.7)$ & $23.7(7.0)$ \\
\hline Working income $(€ /$ month, $t=56)$ & $88(118)$ & $334(123)$ & $204(199)$ & $-191(393)$ \\
\hline Fertility & $-2.4(2.5)$ & $-3.5(4.5)$ & $-4.0(3.9)$ & $-2.1(9.0)$ \\
\hline \multicolumn{5}{|l|}{ Thick support $2-\mathrm{F}(\hat{P}(\mathrm{~W})>5 \%)$} \\
\hline $\mathrm{SE}$ or $\mathrm{RE}\left(\sum_{t=1}^{56}\right)$ & $26.7(1.6)$ & $31.2(2.3)$ & $22.0(2.0)$ & $25.9(2.0)$ \\
\hline Working income $(€ /$ month, $t=56)$ & $54(129)$ & $335(116)$ & $94(183)$ & $334(104)$ \\
\hline Fertility & $-3.4(2.1)$ & $0.3(3.6)$ & $-3.7(3.0)$ & $-0.4(3.2)$ \\
\hline \multicolumn{5}{|l|}{ Optimal subpopulation } \\
\hline $\mathrm{SE}$ or $\mathrm{RE}\left(\sum_{t=1}^{56}\right)$ & $27.0(1.4)$ & $28.4(1.8)$ & $21.5(1.8)$ & $25.9(2.2)$ \\
\hline Working income $(€ /$ month, $t=56)$ & $135(86)$ & $351(114)$ & $208(144)$ & $334(108)$ \\
\hline Fertility & $-3.9(2.1)$ & $0.7(3.0)$ & $-3.2(3.4)$ & $-0.4(3.3)$ \\
\hline \multicolumn{5}{|l|}{ C) Conditional difference-in-difference } \\
\hline CDID1: SE or RE $\left(\sum_{t=1}^{56}\right)$ & $26.3(1.4)$ & $29.2(2.3)$ & $21.2(1.6)$ & $23.9(1.8)$ \\
\hline CDID2: SE or $\operatorname{RE}\left(\sum_{t=1}^{5}\right)$ & $26.1(1.6)$ & $29.1(2.5)$ & $20.8(1.6)$ & $23.7(2.2)$ \\
\hline CDID3: $\mathrm{SE}$ or $\mathrm{RE}\left(\sum_{t=1}^{56}\right)$ & $25.5(1.7)$ & $28.5(2.6)$ & $21.4(1.6)$ & $21.7(2.1)$ \\
\hline CDID4: Working income $(€ /$ month, $t=56)$ & $119(97)$ & 427 (128) & $369(165)$ & $-19(130)$ \\
\hline
\end{tabular}

Notes: Depicted are average treatment effects on the treated as the difference in outcome variables between participants and non-participants. Thereby, the outcome variable "self-employment or regular employment" ("share with at least one maternity or parental leave within the observation window") is depicted by "SE or RE" ("Fertility"). Standard errors are in parentheses and are based on bootstrapping with 200 replications. SUS - Start-up subsidy, BA - Bridging allowance, NP - Non-participation. Common support condition: Thick support: We estimate the effects 1) in a region defined by $0.33<\hat{P}(W)<0.67$ and 2$)$ we divide the propensity score distribution into ten deciles and estimate the effects only in regions where we have a density of at least $5 \%$ in both groups (participants and non-participants) respectively. Optimal subpopulation: The analysis is restricted to a subset of the original sample by keeping individuals with propensity scores inside an optimal common support range $(\alpha<\hat{P}(W)<(1-\alpha))$. The optimal cut-off point $\alpha$ is calculated by using optselect.ado which basically balances two opposing impacts on the variance of the estimated effect (see Crump, Hotz, Imbens, and Mitnik, 2009).

Conditional difference-in-difference: The reference levels for the pre-treatment period are defined as follows: CDID1: July 1998June 2003; CDID2: January 2001-June 2003; CDID3: July 1998-Dec. 2000; CDID4: Average monthly total income in 2002. The fertility outcome is not considered as we have no information on periods spend in maternity or parental leave for the pre-treatment period. 
Table B.2: Sensitivity to Unobserved Heterogeneity: Simulation Approach

\begin{tabular}{|c|c|c|c|c|}
\hline & \multicolumn{2}{|c|}{$\begin{array}{l}\text { Start-up Subsidy vs. } \\
\text { Non-Participation }\end{array}$} & \multicolumn{2}{|c|}{$\begin{array}{l}\text { Bridging Allowance vs. } \\
\text { Non-Participation }\end{array}$} \\
\hline & West Germany & East Germany & West Germany & East Germany \\
\hline \multicolumn{5}{|c|}{ No unobserved heterogeneity (compare Table 5) } \\
\hline $\mathrm{SE}$ or $\mathrm{RE}\left(\sum_{t=1}^{56}\right)$ & $26.9(1.4)$ & $29.8(2.7)$ & $20.6(1.7)$ & $25.9(2.1)$ \\
\hline Working income $(€ /$ month, $t=56)$ & $138(84)$ & $348(105)$ & $225(137)$ & $334(100)$ \\
\hline Fertility & $-3.3(2.1)$ & $2.4(3.3)$ & $-4.4(3.5)$ & $-0.4(3.1)$ \\
\hline \multicolumn{5}{|c|}{ Confounder with an influence like (compare PS estimation in Table A.2) } \\
\hline \multicolumn{5}{|c|}{ 1) Duration of previous unemployment ( $\geq 1$ month $-<3$ months) } \\
\hline $\mathrm{SE}$ or $\mathrm{RE}\left(\sum_{t=1}^{56}\right)$ & $27.4(1.4)$ & $30.7(3.1)$ & $20.6(2.1)$ & $26.9(2.4)$ \\
\hline Working income $(€ /$ month, $t=56)$ & $141(91)$ & $362(118)$ & $227(161)$ & $367(116)$ \\
\hline Fertility & $-3.2(2.0)$ & $1.9(3.7)$ & $-4.5(3.6)$ & $-0.7(3.4)$ \\
\hline \multicolumn{5}{|l|}{ 2) Parents are/were self-employed } \\
\hline $\mathrm{SE}$ or $\mathrm{RE}\left(\sum_{t=1}^{56}\right)$ & $27.0(1.4)$ & $29.5(3.2)$ & $20.5(2.1)$ & $27.0(2.2)$ \\
\hline Working income $(€ /$ month, $t=56)$ & $141(90)$ & $348(122)$ & $220(162)$ & $380(112)$ \\
\hline Fertility & $-3.4(2.1)$ & $1.6(3.8)$ & $-4.6(3.6)$ & $-0.7(3.2)$ \\
\hline
\end{tabular}

Notes: The outcome variable "self-employment or regular employment" ("share with at least one maternity or parental leave within the observation window") is depicted by "SE or RE" ("Fertility"). SUS - Start-up subsidy, BA - Bridging allowance, NP - Non-participation.

No unobserved heterogeneity: Depicted are average treatment effects on the treated as estimated in our main analysis. Standard errors are in parentheses and are based on bootstrapping with 200 replications.

Simulation approach: Depicted are average treatment effects on the treated estimated by assuming the presence of unobserved heterogeneity with an influence like selected confounders. Standard errors are in parentheses and are based on bootstrapping with 200 replications. Results are achieved by using sensatt.ado (Nannicini, 2007). 